\title{
El papel de la opinión publicada en la prensa escrita colombiana antes del plebiscito del 2 de octubre de 2016
}

\section{Juan Carlos Gómez-Giraldo ${ }^{1}$ Juan David Cárdenas-Ruiz²}

Recibido: 2017-12-15

Enviado a pares: 2018-02-07
Aprobado por pares: 2018-03-09

Aceptado: 2018-04-23

DOI: 10.5294/pacla.2019.22.1.9

Para citar este artículo / to reference this article / para citar este artigo Gómez-Giraldo, J. C. y Cárdenas-Ruiz, J. D. (2019). El papel de la opinión publicada en la prensa escrita colombiana antes del plebiscito del 2 de octubre de 2016. Palabra Clave 22(1), e2219. DOI: 10.5294/pacla.2019.22.1.9

\section{Resumen}

El presente artículo recoge los resultados de una investigación descriptiva realizada por investigadores del Observatorio de Medios de la Facultad de Comunicación de la Universidad de La Sabana sobre el papel de la opinión publicada en la prensa de referencia de Colombia durante la etapa previa al plebiscito del 2 de octubre de 2016 con el cual el Gobierno del presidente Juan Manuel Santos Calderón pretendió refrendar los acuerdos de paz con las Fuerzas Armadas Revolucionarias de Colombia (FARC). Con la metodología del análisis de contenido, se analizaron 466 piezas de opinión publicadas por los principales medios impresos nacionales y regionales de Colombia relacionadas con el plebiscito. Se evidenció, entre otras cosas, la primacía de los recursos persuasivos emocionales sobre los racionales, una mayor presencia de marcos de interpretación episódicos por encima de los temáticos y una fuerte connotación política, social y cultural dentro de la

orcid.org/0000-0003-1282-7526. Universidad de La Sabana, Colombia. juan.gomez@unisabana.edu.co

2 orcid.org/0000-0003-4823-1572. Universidad de La Sabana, Colombia. juancar@unisabana.edu.co 
argumentación a favor o en contra de aprobar los acuerdos de La Habana. Las estrategias persuasivas involucraron la utilización de valores, o bien su exaltación, o bien la amenaza de su continuidad, sobre todo, en aspectos centrales de la matriz de cultura política de los colombianos, como el riesgo del cambio de modelo económico, la hipotética amenaza al sistema democrático o la desestabilización de referentes sociales y morales como la estructura familiar.

\section{Palabras clave (fuente: tesauro de la Unesco)}

Plebiscito; opinión publicada; proceso de paz; ciudadano; democracia. 


\section{The Role of Opinions Published in the Colombian Press before the Plebiscite of October 2, 2016}

\section{Abstract}

This article gathers the results of a descriptive research project conducted by researchers from the Media Observatory of the School of Communication at the Universidad de La Sabana. It discusses the role of opinions published in the Colombian press before the plebiscite of October 2, 2016 with which the Government of President Juan Manuel Santos Calderón intended to endorse the peace agreements reached with the Revolutionary Armed Forces of Colombia (FARC). Using the content analysis method, 466 plebiscite-related opinions published by the main national and regional printed media in Colombia were analyzed. We noted, among other things, the primacy of emotional persuasive resources over rational ones, greater presence of episodic interpretation frameworks over thematic ones, and a strong political, social and cultural connotation within the arguments for or against approving the Havana peace accords. Persuasive strategies included the use of values, either their exaltation or threatened continuity, especially in central aspects of the Colombian political culture matrix such as the risk of changing the economic model, the hypothetical threat to the democratic system, or the destabilization of social and moral models such as the family structure.

\section{Keywords (source: Unesco Thesaurus)}

Plebiscite; published opinion; peace process; citizen; democracy. 


\section{0 papel da opinião publicada na imprensa colombiana antes do plebiscito de 2 de outubro de 2016}

\section{Resumo}

Este artigo apresenta os resultados de uma pesquisa descritiva realizado por pesquisadores do Observatorio de Medios da Faculdade de Comunicação da Universidad de La Sabana sobre o papel da opinião publicada na imprensa de referência da Colômbia durante a etapa prévia ao plebiscito de 2 de outubro de 2016, com o qual o governo do presidente Juan Manuel Santos Calderón fez um referendo sobre os acordos de paz com as Forças Armadas Revolucionárias da Colômbia (Farc). Com a metodologia de análise de conteúdo, foram analisadas 466 peças de opinião publicadas pelos principais meios impressos nacionais e regionais da Colômbia relacionados ao plebiscito. Evidenciaram-se, entre outras coisas, a primazia dos recursos persuasivos emocionais sobre os racionais, uma maior presença de marcos de interpretação episódicos em relação aos temáticos e uma forte conotação política, social e cultural dentro da argumentação a favor ou contra a aprovação dos acordos de Havana. As estratégias persuasivas envolveram o uso de valores, sua exaltação ou a ameaça de sua continuidade, especialmente em aspectos centrais da matriz de cultura política dos colombianos, como o risco de mudança do modelo econômico, a ameaça hipotética do sistema democrático ou a desestabilização de referentes sociais e morais, como a estrutura familiar.

\section{Palavras-chave (fonte: tesauro da Unesco)}

Plebiscito; opinião publicada; processo de paz; cidadão; democracia. 
Lo que llamamos realidad es resultado de la comunicación.

Watzlawick

\section{El contexto global y local}

El 2016 fue significativo para todos aquellos que se dedican al estudio de la comunicación pública, porque se presentaron tres fenómenos de interés mundial que contradijeron las apuestas de políticos y medios de comunicación frente al comportamiento de la opinión pública y los electores.

Uno de esos fenómenos, el brexit, ${ }^{3}$ ocurrió el 23 de junio de 2016 en el Reino Unido cuando el Gobierno convocó a los ciudadanos a un referendo para determinar la permanencia de este en la Unión Europea (UE). La pregunta "iDebe el Reino Unido seguir siendo un miembro de la Unión Europea o debe abandonar la Unión Europea?” fue respondida por casi 34 millones de británicos (con el $72 \%$ de participación), quienes decidieron la salida con el $51 \%$ de los votos y una diferencia de 833000 sufragios (BBC Mundo, 2016). Estos resultados llevaron a la dimisión del primer ministro David Cameron y cambiaron el mapa geopolítico de Europa.

Otro de los acontecimientos que concitó el análisis de los estudiosos de la comunicación pública fueron las elecciones presidenciales en los Estrados Unidos, hecho que cada cuatrienio apunta el reflector mundial al país norteamericano, pero que en esta oportunidad ofreció lecciones aparentemente inéditas, dignas de reflexiones académicas. Donald Trump fue elegido con 306 votos del Colegio Electoral frente a Hillary Clinton con 232, pese a que el elector primario prefirió a la demócrata por encima del republicano: el 48,53 \% vs. el 46,42 \% (PBS Newshour, 2017). Resultado producto de una amalgama en el democrático escenario de la democracia por antonomasia: política + business + medios de comunicación + redes sociales + infotainment $=$ the apprentice president .

El empresario había captado por años la atención de los estadounidenses a través de los medios de comunicación, y estos últimos, arrepentidos de su "creación", en concomitancia con la forma en que lo expresó

3 Brexit es un acrónimo inglés compuesto de los términos Britain y exit. 


\section{Amón (2016), invitaban al final de la campaña de Donald Trump a que se abstuvieran de votar por él:}

Trump proporcionaba audiencia. Interesaba a los americanos. Protagonizaba un experimento sociológico y comercial en la edad volátil de la política espectáculo, pero las grandes televisiones subestimaron la posibilidad de que la criatura decidiera instrumentalizarlas, emanciparse de ellas. Ya lo había hecho el monstruo de Frankenstein. Escapó del laboratorio para despojarse de su creador. La diferencia es que Trump no ha sido ajusticiado por la masa en una persecución de antorchas, sino llevado en volandas al despacho oval de la Casa Blanca, significando, de fondo y de forma, la inocuidad o la irrelevancia de las consignas editoriales. (párr. 2)

Estos eventos políticos de importancia global intensificaron el uso de términos tales como post-truth, ${ }^{4}$ adjetivo anglosajón, y postfaktisch, ${ }^{5}$ vocablo alemán, traducidos como "posverdad" y "posfactual", respectivamente, relacionados con el proceso de configuración de la opinión pública, considerados los conceptos del año en 2016 por los académicos del Diccionario Oxford y por la Academia Alemana de la Lengua y la Poesía, y convertidos en tema de investigación en todas las latitudes.

El tercer fenómeno con características similares a los del Reino Unido y los Estados Unidos se presentó en Colombia con el plebiscito del 2 de octubre de 2016, mecanismo a través del cual el Gobierno del presidente Juan Manuel Santos pretendió refrendar los acuerdos de paz alcanzados con las Fuerzas Armadas Revolucionarias de Colombia ${ }^{6}$ (FARC) en La Haba-

4 "En relación con o denota circunstancias en las que los hechos objetivos influyen menos en la formación de la opinión pública que los llamamientos a la emoción y a las creencias personales” (Oxford Dictionaries, s. f.).

5 "En el debate político y social crece la importancia de las emociones frente a los hechos [...] y 'en este sentido la palabra postfactual ( $\mathrm{sic}$ ) representa un profundo cambio político.' El término 'post factual' ( $\mathrm{sic}$ ), en especial asociado a la política, se refiere a aquellos discursos políticos que tienen poco respeto por la realidad, los hechos y la evidencia" (ANSA Latina, 2016).

6 Este grupo insurgente que firmó el acuerdo de paz con el Gobierno de Juan Manuel Santos el 24 de noviembre de 2016, nació — según sus militantes - el 27 de mayo de 1964 cuando un grupo de guerrilleros comandados por Pedro Antonio Marín Marín, alias "Manuel Marulanda Vélez", se enfrentó a una brigada del Ejército en un sitio conocido como La Floresta, parte media del cañón del río Atá, operativo oficial que hizo parte de la Operación Soberanía o Plan Laso, que pretendió acabar con las que Álvaro Gómez Hurtado denominó en el Senado "repúblicas independientes". Luego, durante la II Conferencia del Bloque Simón Bolívar, en abril de 1966, el grupo alzado en armas adoptó oficialmente el nombre de Fuerzas Armadas Revolucionarias de Colombia (FARC) (Villamizar, 2017, pp. 262-293). 
na. Luego de una negociación que duró cerca de cinco años, se consultó al constituyente primario con la pregunta cerrada (Sí o No): “¿Apoya usted el acuerdo final para la terminación del conflicto y la construcción de una paz estable y duradera?”. El No ganó con el 50,21 \% de los votos (6 431376 ) frente al Sí con el 49,78\% de los sufragios (6 377 482), una diferencia de 53894 votos y una participación de apenas el 37 \% del censo electoral (Registraduría Nacional del Estado Civil, 2016).

Este triunfo fue una sorpresa total y generalizada, según las cifras y el discurso previo indicaban lo contrario:

- Incluso el expresidente de Colombia y líder de la campaña por el No, Álvaro Uribe Vélez, presentía la derrota cuando afirmaba seis días antes de la jornada electoral: "Nos duele que democracias amigas acudan a avalar la impunidad disfrazada al cartel de cocaína más grande del mundo. Nos duele que concurran a darle aprobación a un plebiscito de democracia recortada" (Infobae.com, 2016).

- En una encuesta realizada por la firma Ipsos Napoleón Franco y contratada por la alianza de medios conformada por RCN Radio, RCN Televisión, La FM y Semana, publicada el 27 de septiembre de 2016, a una semana del plebiscito, el Sí obtenía el $66 \%$ de la intención del voto ciudadano $v s$. un $34 \%$ del No (Semana, 2016).

- Otra encuesta, de la empresa Datexco, arrojó que el 55 \% de los ciudadanos apoyaría los acuerdos de La Habana, mientras que un 36,6\% votaría por el No. Y según la encuestadora Cifras \& Conceptos triunfaría el Sí con un 54 \% de los votos (Infobae.com, 2016).

\section{Las élites desconectadas de los ciudadanos}

Lo ocurrido en Colombia con el plebiscito conjugó el desacierto de las firmas encuestadoras y la presencia de un hecho al que las organizaciones políticas están en mora de tomar en consideración: el ciudadano es el núcleo de la cuestión, la voz ciudadana cuenta y en la política no existe una sola razón para que al ciudadano se le considere un convidado de piedra en las discusiones de la agenda pública. Y esta es tal vez la primera simple y gran evidencia que ha venido a gritarle a la sociedad contemporánea el universo de las nuevas tecnologías de la información y la comunicación 
(TIC) a través de su mayor constelación, las redes sociales: el ciudadano actúa conforme a intereses propios que transitan una ruta connatural alejada de la capacidad manipuladora del poder. Ese fue el denominador común en los tres casos citados, en los que se observó la desconexión entre las élites (políticos, líderes de opinión y medios de comunicación ${ }^{7}$ ) y los intereses, las necesidades y el sentir de la gente de a pie; y en esa desconexión, suele ganar la coherencia y perder (consecuentemente) la desconexión (o los desconectados).

Los ciudadanos mantuvieron, desde el inicio hasta el final de las negociaciones, su opinión respecto de los temas principales de la negociación en La Habana, según se colige de un trabajo previo del Observatorio de Medios de la Facultad de Comunicación de la Universidad de La Sabana, en el que se consultó de manera periódica a los mayores de edad residentes en Bogotá a través de seis encuestas, la primera en abril de 2013 y la última en agosto de $2016 ;^{8}$ en todas ellas, se hicieron las mismas preguntas y los participantes mantuvieron su posición respecto de 1) la posibilidad del perdón a las FARC por parte de la sociedad colombiana, 2) la eventual participación política de las FARC luego de una desmovilización y entrega de armas, 3) la reincorporación a la vida civil y 4) la posibilidad del castigo a los delitos cometidos por los guerrilleros con penas alternativas.

7 Cuando se hace referencia a la posición de los medios de comunicación frente a temas de discusión pública, conviene siempre tener en consideración la propiedad de ese sistema mediático. En Colombia, hay un buen trabajo, “¿De quien son lo medios?", de Monitoreo de la Propiedad de Medios, que ha elaborado un completo mapa que registra los nombres de personas y grupos económicos propietarios de los medios de comunicación de este país.

8 Las encuestas fueron realizadas por el Observatorio de Medios con la participación de los alumnos del Seminario de Investigación en Comunicación Pública de la Facultad de Comunicación de la Universidad de La Sabana en abril y octubre de 2013, en marzo y octubre de 2014 y en marzo y agosto de 2016. En las mediciones del primer año (2013), se tomó como universo una población de 5497571 ciudadanos mayores de 18 años, según el censo de población realizado por el Departamento Administrativo Nacional de Estadística (DANE) de 2005 con su correspondiente proyección a 2013, para una muestra de 778 encuestados, con un margen de confiabilidad del $95 \%$ y un margen de error máximo permitido del 3,1 \%. El cuestionario de la encuenta se aplicó en 19 de las 20 localidades del Distrito Capital (se excluyó la zona rural que es poco significativa estadísticamente por su baja población) por un método de muestreo probabilístico multietápico con afijación proporcional por sexo y edad. En 2014, la proyección de la población bogotana, según el DANE, fue de 5584708 ciudadanos, con una muestra de 780 encuestados con idénticos márgenes de confiabilidad y de error, similar proceso de muestreo y en las mismas localidades. En 2016, la proyección de la población de ciudadanos mayores de 18 años residentes en Bogotá, de acuerdo con el DANE, fue de 5794015 , y según este universo, se calculó una muestra de 960 unidades con un margen de error calculado en el 3,5\% y un margen de confiabilidad del $95 \%$; encuestas aplicadas con el mismo proceso y calidad del muestreo probabilístico. 
En la figura 1, se observa la reticencia ciudadana a una eventual participación política por parte de los insurgentes, así como el bajo interés manifiesto en torno al asunto del perdón durante los cuatro años en los que se hicieron las mediciones; en la primera medición en abril de 2013, con la euforia inicial del proceso, solo el $27 \%$ de los consultados se manifestaron a favor de la participación política de los desmovilizados de las FARC, indicadores que se fueron reduciendo a medida que avanzaba el proceso (en octubre de 2013 se registró un $26 \%$; en marzo de 2014, bajó tres puntos; una reducción similar se observó en octubre de 2014; en marzo de 2016, la cifra de apoyo a la participación política fue apenas del $13 \%$ y en agosto de 2016 llegó al $24 \%$ ).

\section{Figura 1. Opinión de los bogotanos frente a concesioines del Gobierno ante un eventual acuerdo de paz con las FARC.}

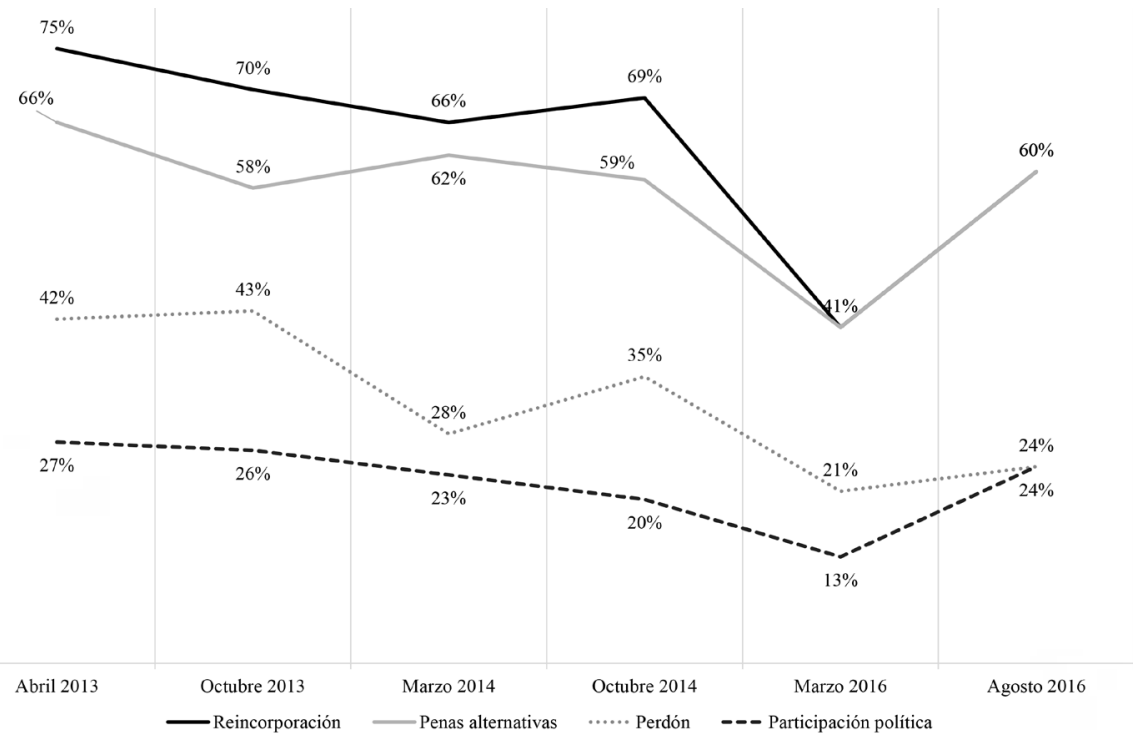

Fuente: Gómez y Cárdenas (2017, p. 169).

Respecto de la disposición de los encuestados a perdonar los delitos cometidos por las FARC, las primeras mediciones mostraban que al inicio (2013) solo el $42 \%$ estaban dispuestos a perdonar y, de manera paulatina, ese porcentaje se redujo hasta llegar, en la medición de agosto de 2016, a un 24 \% (Gómez y Cárdenas, 2017, p. 169). 
En cuanto a las preguntas atinentes a la posibilidad de la reincorporación a la vida civil de los desmovilizados y la alternatividad penal, los consultados expresaron posiciones más flexibles en indicadores que iniciaron con altos porcentajes (el 75 y el $66 \%$, respectivamente) y que concluyeron con un 60 \% de respaldo ciudadano (Gómez y Cárdenas, 2017, p. 169).

\section{Una amplia investigación y su metodología, el estudio específico y sus objetivos}

\section{Investigación sobre los discursos del proceso de paz}

Los resultados que se presentan en este artículo hacen parte de una gran investigación que realiza el Observatorio de Medios de la Facultad de Comunicación de la Universidad de La Sabana sobre la manera como los protagonistas del proceso de paz comunicaron lo que allí se discutió durante los años que duró la negociación entre el Gobierno de Juan Manuel Santos y las FARC.

Con este fin, se divide el discurrir comunicativo en tres planos básicos: un plano de activación en el que se estudian las intenciones de quienes elaboran y expresan discursos sobre la negociación, un plano de cubrimiento que analiza el contenido mediático y, por último, un plano de entendimiento que consulta la opinión de los ciudadanos respecto de lo expresado por los negociadores e informado en la agenda mediática (Canel, 2009; Cragan y Shields, 1995; Entman, 2004; García, 2010; Gómez Giraldo, 2013). La metodología empleada hace una triangulación en la que se mide 1) la intencionalidad del frame elaborado por los negociadores en La Habana y los líderes políticos de la oposición (plano de activación), 2) la capacidad de esos frames de permear a los medios de comunicación e instalarse en las agendas de discusión pública (plano de cubrimiento) y 3 ) la eficacia de esa interpretación de la realidad para ajustarse a las expectativas y la comprensión de las audiencias o ciudadanos (plano de entendimiento) (García, 2013, pp. 192-193).

Para lograr los objetivos propuestos, se hizo un seguimiento pormenorizado a lo acontecido en la negociación de paz durante sesenta meses, 
actividad que se inició en agosto de 2012, una vez que las partes involucradas anunciaron la apertura oficial de la negociación, y concluyó en julio de 2017. Se recogieron los discursos de negociadores y oposición de los momentos clave del proceso (plano de activación); se determinaron los medios de referencia para hacer seguimiento a sus publicaciones sobre la negociación (plano de cubrimiento) y se elaboró con el apoyo de Siglo Data MMI una base de datos compuesta por 155552 piezas informativas publicadas por los quince medios de comunicación de referencia del país según las categorías prensa (El Tiempo, El Espectador, El Colombiano, El País, El Heraldo y Semana), radio (Caracol Básica, RCN Básica, La W, La FMy Blu Radio) y televisión (Canal Caracol, Canal RCN, CM\& y Noticias Uno); y se hicieron seis encuestas en Bogotá (abril de 2013, octubre de 2013, marzo de 2014, octubre de 2014, marzo de 2016 y agosto de 2016) en las que se consultó a los ciudadanos su opinión respecto de los temas comunicados por los actores del proceso a través de los medios de comunicación.

\section{La opinión publicada sobre el plebiscito}

Como apéndice de esta gran investigación, se quiso aprovechar la información recopilada y se acordó hacer un seguimiento específico a uno de los momentos clave del proceso de paz, el plebiscito del 2 de octubre de 2016, dada su importancia como mecanismo de refrendación a los acuerdos de La Habana. En esta ocasión, se observó y analizó el contenido de las piezas publicadas en las páginas de opinión de los principales periódicos del país para identificar los elementos empíricos que sirvieron de soporte a los argumentos expuestos respecto del papel que desempeñó la opinión publicada ${ }^{9}$ en la configuración de la opinión pública expresada por los colombianos en el plebiscito del 2 de octubre de 2016.

El Observatorio de Medios recogió todas las piezas de opinión publicadas en los diarios y las revistas de referencia ${ }^{10}$ durante los cuarenta días previos a la refrendación, es decir, desde el 24 de agosto de 2016 (día de cierre de las negociaciones entre delegados del Gobierno de Colombia y

9 Con el concepto opinión publicada, los autores de esta investigación se refieren a aquella que se expresa en las páginas editoriales y de opinión de los diarios y revistas del país.

10 Los diarios y revistas de referencia son aquellos de mayor circulación certificada en Colombia. 
las FARC) hasta el día de la votación en las urnas. En total, Siglo Data MMI suministró a los investigadores ${ }^{11}$ un universo compuesto por 466 piezas de opinión, distribuidas con la siguiente frecuencia y participación según el medio (tabla 1).

\section{Tabla 1. Distribución del universo analizado según medios}

\begin{tabular}{|c|c|c|}
\hline Nombre del medio & Frecuencia & Porcentaje (\%) \\
\hline El Colombiano & 119 & 26 \\
\hline El Espectador & 116 & 25 \\
\hline El Tiempo & 102 & 22 \\
\hline El País & 70 & 15 \\
\hline El Heraldo & 53 & 11 \\
\hline Semana & 6 & 1 \\
\hline Total & $\mathbf{4 6 6}$ & $\mathbf{1 0 0}$ \\
\hline
\end{tabular}

Fuente: elaboración propia.

La investigación descriptiva que se presenta se planteó como objetivo general analizar los contenidos de las piezas de opinión publicadas por la prensa escrita colombiana durante los cuarenta días previos a la realización del plebiscito, para determinar en ellas las posturas y los argumentos de la opinión publicada frente a tan crucial tema de la vida política nacional. Y posteriormente comparar ese análisis del contenido con los resultados del escrutinio para determinar si la opinión que se publicó logró influir en la decisión de los ciudadanos que acudieron a las urnas.

En el proceso, se estructuró una matriz que contempló variables generales para identificar de manera apropiada cada una de las piezas de opinión ${ }^{12}$ y su origen, la ubicación de los contenidos en primera página y en páginas editoriales, el subgénero, ${ }^{13}$ el autor (si el artículo está firmado por

11 Los investigadores principales fueron apoyados por el semillero conformado por los estudiantes Cristina Angarita, Estefanía Daza, Sebastián Villate, Juan David Botero y Esteban Beltrán.

12 Los artículos de opinión son definidos como "escrito de muy variado y amplio contenido, de varia y muy diversa forma, en el que se interpreta, valora o explica un hecho o una idea actuales, de especial trascendencia, según la convicción del articulista" (Martín Vivaldi, 1973, p. 176).

13 Se acude a la clasificación hecha por José Luis Martínez Albertos en su Curso general de redacción periodística, en que destaca el estilo de solicitación y presenta como tipos de este a los editoriales, los comentarios, las críticas, los 
el medio que lo publica, un columnista o un lector) y el sexo del autor (Gómez, Hernández, Gutiérrez, Arango y Franco, 2010). De igual manera, se acordó observar si el plebiscito era el tema central del contenido de cada pieza y, cuando no era así, cuáles los temas con los que se asociaba el mecanismo de refrendación de los acuerdos de paz.

Como elemento central para el análisis propuesto, se identificó si el articulista tomó una posición respecto del plebiscito y, si así fue, se determinó cuál fue esa postura. Luego, se consideró el tipo de argumentos esgrimidos por los columnistas y los líderes de opinión para expresar su juicio crítico. Para ello, se optó por una clasificación básica que permitiera conocer si esos argumentos estaban sustentados en los hechos que vivía el país (frames episódicos ${ }^{14}$ ) o si estos estaban soportados en cifras, datos, referencias, citas (frames temáticos ${ }^{15}$ ). En este análisis de los soportes argumentativos, se observó, por último, cuáles fueron los valores que apoyaron las posiciones de los articulistas frente al plebiscito.

Luego, con el objetivo de identificar conceptos y actores centrales dentro de la construcción de la opinión publicada, se hizo un conteo de palabras de todo el material analizado. El conteo se enfocó en las palabras en general, y en las instituciones y personas mencionadas, en particular.

Y, por último, se examinó si en los contenidos de los artículos de opinión se valoraba (de manera positiva) la actuación de los negociadores, entiéndase Gobierno, guerrilla u oposición, asunto que permitió advertir cuál de esos actores era mejor ponderado, tanto por los columnistas como por los medios.

\section{Hallazgos generales de la investigación}

De manera preliminar, se puede afirmar que cada medio publicó en promedio 78 piezas; en los periódicos, la media fue de 92 , y en cuanto a las revistas,

escritos sueltos y las tribunas libres (Martínez, 2001, p. 367). En resumen, se clasifican como subgéneros de opinión el editorial, la columna, las glosas o comentarios, las frases y las cartas de los lectores.

14 Los frames episódicos describen eventos concretos y casos particulares que iluminan el problema (Iyengar, 1990, p. 22; Iyengar, 1991, pp. 2, 14, citado por Aarøe, 2011, p. 209).

15 Los frames temáticos se enfocan en asuntos políticos y eventos en un contexto más amplio y presentan evidencia colectiva, abstracta y general (Iyengar, 1990, p. 22; Iyengar, 1991, pp. 2, 14, citado por Aarøe, 2011, p. 209). 
Semana publicó solo 6. Cabe destacar también el amplio interés de la prensa regional en el plebiscito (el $52 \%$ de las piezas de opinión fueron publicadas en los periódicos El Colombiano, ${ }^{16}$ El Heraldo ${ }^{17}$ y El País, ${ }^{18}$ un total de 242 artículos), frente a la prensa nacional que llegó al $48 \%$ (El Tiempo, ${ }^{19}$ El Espectador ${ }^{20}$ y Semana, ${ }^{21}$ medios impresos que publicaron 224 artículos de opinión). Llama la atención, como se puede apreciar en la figura 2, la primera posición en cantidad de columnas y editoriales publicados por el diario regional $\mathrm{El} \mathrm{Co-}$ lombiano de Medellín con 119 artículos (26\% del total), por encima de los diarios de circulación nacional con sede en Bogotá El Espectador con 116 artículos (25\%) y El Tiempo con 102 piezas de opinión (22\%).

\section{Figura 2. Distribución porcentual de las piezas analizadas según medios}

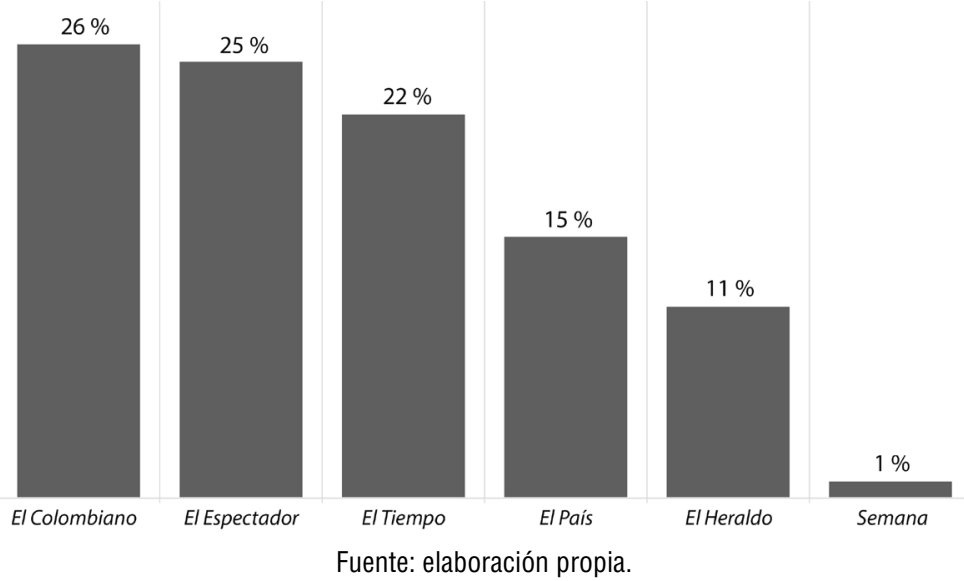

16 El Colombiano es un periódico regional editado en Medellín, capital del departamento de Antioquia, propiedad de las familias Gómez y Hernández que tiene el 4 \% de los lectores de todo el país según el Estudio General de Medios de 2014 (Monitoreo de Medios, s. f.).

17 El Heraldo es un periódico de Barranquilla, capital del departamento del Atlántico, con amplia circulación en el Caribe.

18 El País es editado en Cali, capital del departamento del Valle del Cauca, propiedad de la familia Lloreda, y alcanza, según el Estudio General de Medios de 2014, el 2 \% de participación en el total de lectores de diarios en Colombia (Monitoreo de Medios, s. f.).

19 El Tiempo, propiedad del banquero Luis Carlos Sarmiento Angulo, tiene el $16 \%$ de los lectores de todo el país, según el Estudio General de Medios de 2014 (Monitoreo de Medios, s. f.).

20 El Espectador es un diario de circulación nacional que alcanza el $4 \%$ de los lectores de periódicos del país según el Estudio General de Medios de 2014, es propiedad del grupo Santo Domingo, propietario también de Canal Caracol, Cromos y Blu Radio (Monitoreo de Medios, s. f.).

21 Semana es una revista de propiedad de Felipe López y es la de mayor circulación en el país con un $16 \%$ de los lectores, según el Estudio General de Medios 2014 (Monitoreo de Medios, s. f.). 


\section{Relevancia otorgada por la opinión publicada al plebiscito del 2 de octubre en Colombia}

La relevancia otorgada por la prensa a la información que presenta está dada por una serie de indicadores que van desde la ubicación del texto (en primera página o en páginas interiores), pasando por la extensión o espacio otorgado (esta se mide en páginas, columnas y centímetros), seguido del tipo de ilustración para el acompañamiento o la explicación de lo expuesto, el tipo de pieza periodística (también se denomina género), el tipo de responsabilidad asumida con lo que se informa o se argumenta (esta responsabilidad se asume con la firma) y por el número y tipo de fuentes consultadas y contrastadas por el periodista (Gómez et al., 2010).

Para el caso que ocupa esta investigación, se tomaron como indicadores de relevancia de los artículos de opinión su ubicación (si se hizo un llamado de atención al lector respecto de la importancia dada al tema publicándolo en primera página o en páginas interiores), el tipo de artículo de opinión (editorial, columna, glosa o comentario, frase y carta de los lectores) y, por último, la responsabilidad asumida por el autor con su firma estampada en la pieza.

\section{La opinión sobre el plebiscito en primera plana}

No es corriente que los títulos de los artículos de opinión sean publicados en la primera página de los periódicos o revistas, excepciones que se hacen muy esporádicamente debido a la importancia de quién lo dice o de lo que se dice. Durante el periodo de análisis, se observó que 33 de 466 artículos de opinión estudiados (7\%) fueron destacados en la primera página de los periódicos (figura 3), lo cual indica que este tema alcanzó un alto grado de importancia para los editorialistas de los periódicos estudiados. Como ejemplo de este hallazgo, se puede destacar el artículo editorial de El Colombiano publicado el jueves 1 de septiembre de 2016, "La pregunta del plebiscito", pieza que también fue titulada en la primera página del impreso de esa fecha.

Como se observa en la figura 4, la columna fue el subgénero de opinión que registró mayor frecuencia de uso para expresar la opinión sobre 
el plebiscito, con un $86 \%$ del total de las piezas publicadas. Cabe destacar también que los lectores pudieron expresar su opinión (cartas de los lectores) que alcanzaron un segundo lugar con un $6 \%$ de las piezas, mientras que la institucionalidad de la prensa desde sus editoriales ocupó el tercer puesto, con el $5 \%$ del total de las piezas de opinión publicadas.

\section{Figura 3. La opinión sobre el plebiscito destacada en la primera página de la prensa colombiana}

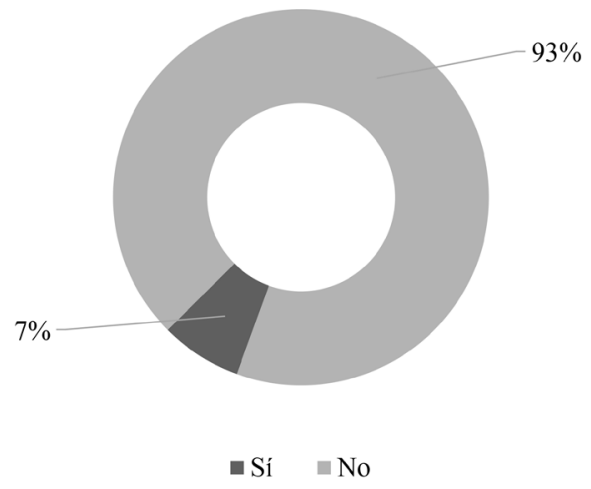

Fuente: elaboración propia.

\section{Figura 4. Tipo de artículo (subgénero periodístico) usado para expresar opiniones sobre el plebiscito}

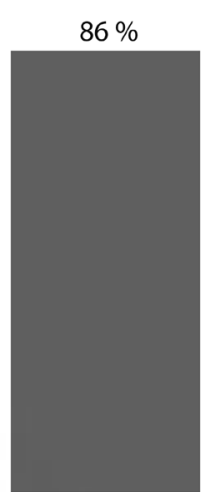

Columna
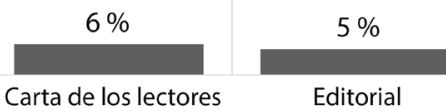

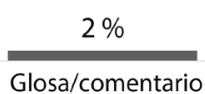

$\frac{1 \%}{\text { Frase destacada }}$

Fuente: elaboración propia. 
La revista y los cinco periódicos analizados tuvieron comportamientos diferentes al definir el subgénero de opinión para expresar sus posiciones respecto del plebiscito. Por ejemplo, dos periódicos regionales (El Heraldo y El Colombiano) fueron los que más editoriales publicaron sobre este mecanismo de participación ciudadana con el 8 y $7 \%$ en su orden, según se aprecia en la tabla 2, mientras que El Espectador solo publicó el 3 \% del total de los editoriales. Semana y este último diario privilegiaron las columnas con el 100 y el $90 \%$, respectivamente.

\section{Tabla 2. Tipo de artículo (subgénero periodístico) usado para expresar opiniones sobre el plebiscito según los medios de comunicación estudiados}

\begin{tabular}{|l|c|c|c|c|c|}
\hline $\begin{array}{c}\text { Medio/ } \\
\text { subgénero }\end{array}$ & Editorial (\%) & Columna (\%) & $\begin{array}{c}\text { Glosa/ } \\
\text { comentario (\%) }\end{array}$ & $\begin{array}{c}\text { Frase destacada } \\
(\%)\end{array}$ & $\begin{array}{c}\text { Cartas de } \\
\text { lectores (\%) }\end{array}$ \\
\hline El Colombiano & 7 & 85 & 5 & 3 & 0 \\
\hline El Espectador & 3 & 90 & 0 & 0 & 8 \\
\hline El Tiempo & 6 & 82 & 0 & 0 & 12 \\
\hline El País & 4 & 89 & 4 & 3 & 0 \\
\hline El Heraldo & 8 & 75 & 0 & 0 & 17 \\
\hline Semana & 0 & 100 & 0 & 0 & 0 \\
\hline Promedio & 4,6 & 86,8 & 1,5 & 1 & 6,1 \\
\hline
\end{tabular}

Fuente: elaboración propia.

\section{Los columnistas asumieron la responsabilidad}

Otro elemento clave que permite calibrar la importancia que se otorga a la opinión que se expresa tiene que ver con asumir la responsabilidad de los contenidos difundidos: la prensa asume esta responsabilidad a través de los editoriales, en las columnas la asume quien firma y, en el caso de los lectores, cuando estos envían la correspondencia a la dirección de los periódicos con nombre y firma (Gómez et al., 2010).

Durante el periodo analizado y la información contenida en la tabla 3, los cinco periódicos expresaron su opinión institucional sobre el plebiscito a través de sus editoriales. Por ejemplo, El Tiempo (2016a), con el titular "Justicia especial, pero no insular", afincó el futuro de los acuerdos y los resultados del plebiscito en la Jurisdicción Especial para la Paz; El País 
(2017) tituló “Por la convivencia”, en que destacó la importancia del plebiscito para el futuro de la democracia e hizo un llamado a los colombianos a respetar la opinión contraria; El Heraldo (2016a), en el editorial "Una nueva etapa", destacó así el rol de los ciudadanos a través del plebiscito: "para cerrar (o no) el capítulo de la guerra”; El Espectador (2016a), para indicar la relevancia de la firma de los acuerdos en Cartagena tituló su editorial "26 de septiembre de 2016"; y El Colombiano (2016b), en el editorial "Dos semanas para elevar el debate", concluyó que las semanas previas al plebiscito "pueden dibujar el panorama de lo que sería una cultura democrática aún por construir, que no excluye el debate intenso ni teme la confrontación dialéctica pero que en todo caso debe excluir la violencia física y verbal".

\section{Tabla 3. Responsable de la opinión expresada}

\begin{tabular}{|l|c|c|}
\hline \multicolumn{1}{|c|}{ Autor } & Frecuencia & Porcentaje (\%) \\
\hline El periódico o revista & 30 & 6 \\
\hline Otro medio de comunicación & 2 & - \\
\hline Columnista & 401 & 87 \\
\hline Lector & 33 & 7 \\
\hline Total & $\mathbf{4 6 6}$ & $\mathbf{1 0 0}$ \\
\hline
\end{tabular}

Fuente: elaboración propia.

\section{La opinión femenina, la opinión masculina}

El Observatorio de Medios midió la opinión publicada sobre el plebiscito según el sexo de los autores de los artículos (varón/mujer), para determinar la participación de cada uno de ellos en los procesos de configuración de la opinión pública nacional sobre esta trascendental cuestión. Más allá de hacer eco de la discusión sobre la perspectiva de género, paralelamente debatida en las redes sociales durante la campaña por el Sí y por el No en el plebiscito, vale la pena subrayar la escasa participación de la mujer (figura 5) en las secciones de opinión de la prensa nacional (8\%) frente a una alta frecuencia de participación masculina (92\%), notable desequilibrio que reclama reflexiones que esta investigación no contempló como objetivo. 


\section{Figura 5. Responsable de la opinión expresada según el sexo del autor}

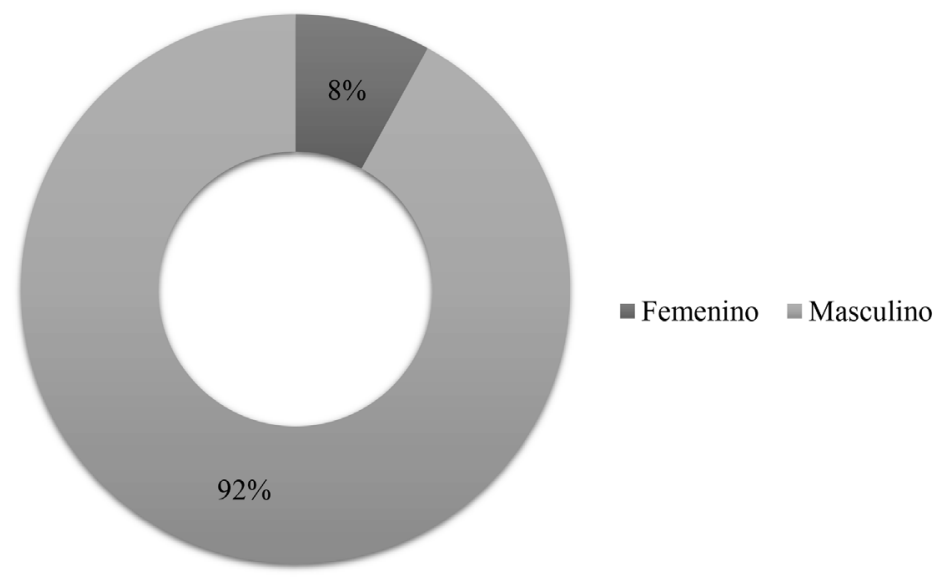

Fuente: elaboración propia.

A este respecto, y como se aprecia en la tabla 4, el comportamiento de los periódicos fue diverso. Por ejemplo, El Heraldo destinó mayor espacio a la opinión femenina (20\%) con columnistas como Tatiana Dangond, Cecilia López Montaño, Lola Salcedo, Claudia Ayola, Mónica Gontovnik, Catalina Ruiz Navarro y Bertha C. Ramos; El Espectador (17 \%) publicó artículos de Catalina Ruiz Navarro, Ana Milena Muñoz de Gaviria, Melba Escobar, Aura Lucía Mera, Piedad Bonnett, Tatiana Acevedo, Claudia Morales, Cecilia Orozco Tascón, Cristina de la Torre, Yolanda Ruiz, Elisabeth Ungar, María Paula Saffón, Viviam Newman y Patricia Lara Salive; El Tiempo (14 \%) contó con colaboraciones de María Isabel Rueda, Cecilia López Montaño, Adriana La Rotta, Margarita Rosa de Francisco, Cecilia Álvarez Correa, Socorro Ramírez, Laura Gil, Claudia López, Catalina Cock D. y Lucy Nieto de Samper; El Colombiano (11\%) tuvo el aporte de colaboradoras habituales como Ana Cristina Aristizábal Uribe, Cristina de Toro, Martha Lucía Ramírez, Ana Cristina Restrepo Jiménez, María Clara Ospina, Elbacé Restrepo y Enoris Restrepo de Martínez; y por último, El País ( $8 \%$ ) publicó piezas de opinión escritas por Melba Escobar, Patricia Lara Salive, María Elvira Bonilla, Carolina Toledo Patterson, Paola Andrea Gómez, Beatriz López, Ángela Cuevas de Dolmetsca, Gloria H. y Aura Lucía Mera. 


\section{Tabla 4. Responsable de la opinión expresada según el sexo del autor y el medio de comunicación}

\begin{tabular}{|c|c|c|}
\hline Medio & Mujer (\%) & Varón (\%) \\
\hline El Tiempo & 14 & 86 \\
\hline Semana & 17 & 83 \\
\hline El Espectador & 18 & 82 \\
\hline El País & 8 & 92 \\
\hline El Heraldo & 20 & 80 \\
\hline El Colombiano & 11 & 89 \\
\hline
\end{tabular}

Fuente: elaboración propia.

\section{El ranking de los columnistas de opinión sobre el plebiscito}

Los columnistas que con mayor frecuencia se refirieron al plebiscito o a temas con él relacionados en el periodo de análisis comprendido entre el 24 de agosto y el 2 de octubre de 2016 fueron los siguientes (tabla 5).

\section{Tabla 5. Líderes de opinión con el mayor número de columnas publicadas sobre el plebiscito}

\begin{tabular}{|l|c|}
\hline Nombre del autor de la pieza de opinión & Frecuencia \\
\hline Francisco de Roux & 7 \\
\hline Alberto Velásquez Martínez & 5 \\
\hline Rudolf Hommes & 5 \\
\hline Alejo Vargas Velásquez & 4 \\
\hline Carlos Duque & 4 \\
\hline Fernando Cepeda Ulloa & 4 \\
\hline Jorge Restrepo Potes & 4 \\
\hline Juan David Escobar Valencia & 4 \\
\hline Juan Gómez Martínez & 4 \\
\hline Mario Morales & 4 \\
\hline Poncho Rentería & 4 \\
\hline Rodrigo Uprimny & 4 \\
\hline Carlos Caballero & 3 \\
\hline Cecilia López Montaño & 3 \\
\hline Cristina de la Torre & 3 \\
\hline Diego Martínez Lloreda & \\
\hline
\end{tabular}




\begin{tabular}{|l|c|}
\hline Nombre del autor de la pieza de opinión & Frecuencia \\
\hline Felipe Zuleta Lleras & 3 \\
\hline Francisco Cortés Rodas & 3 \\
\hline Gustavo Gómez & 3 \\
\hline Juan Camilo Restrepo & 3 \\
\hline Juan José García Posada & 3 \\
\hline Juan Pablo Ruiz Soto & 3 \\
\hline Julio César Londoño & 3 \\
\hline Luis Fernando Álvarez Jaramillo & 3 \\
\hline Luis Guillermo Restrepo & 3 \\
\hline Luis Noé Ochoa & 3 \\
\hline María Elvira Bonilla & 3 \\
\hline Mauricio Vargas & 3 \\
\hline Rafael Nieto Loaiza & 3 \\
\hline Ramiro Bejarano Guzmán & 3 \\
\hline Raúl E. Tamayo Gaviria & 3 \\
\hline Ricardo Silva & 3 \\
\hline Tola y Maruja & 3 \\
\hline & 3 \\
\hline
\end{tabular}

Fuente: elaboración propia.

En la tabla 5, se incluyen los columnistas que publicaron tres o más piezas de opinión, frecuencia que significó un registro superior al $1 \%$. El listado está encabezado por el sacerdote jesuita Francisco de Roux, columnista de El Tiempo ("La Paz desde la ética de lo neutral", "Mi voto", "El perdón increíble", "Vamos por el ser humano" y "Un voto ante la vida”) y El Colombiano ("Voto en conciencia" y "Domingo del plebiscito") con siete publicaciones; seguido del exdirector de El Colombiano, economista y diplomático Alberto Velásquez Martínez con cinco columnas ("Maniqueísmo clerical”, "Estalló la paz”, Bájense de la nube”, "Dictadura constitucional” y "La astucia presidencial"); y por Rudolf Hommes, exministro de Hacienda y columnista de El Tiempo ("En el lugar del otro" y "Los imparciales"), El Colombiano ("La paz y la reforma tributaria"), El Heraldo ("Paz y reforma tributaria”) y El País (“QQué sigue?”) también con cinco columnas. Solo tres mujeres aparecen entre los 33 columnistas con mayor frecuencia de publicación: Cecilia López Montaño en El Heraldo ("No demos reversa" 
y “Digan lo que digan”) y en El Tiempo (“¿Cómo se financiaría el posconflicto?”); Cristina de la Torre, de El Espectador ("Partidos a reinventarse”, "Impunidad de cuello blanco” y “¿Ocaso del lenguaje traqueto?”); y María Elvira Bonilla de El País ("El coco de la justicia”, "Usted sabe que nos va a matar" y "Santos, un paso al costado").

\section{Posición de la opinión publicada frente al plebiscito}

Debido a la experiencia adquirida por el país en el proceso de paz llevado a cabo en el Gobierno de Andrés Pastrana (1998-2002) con las FARC, frustrada negociación que duró más de tres años e incluyó el despeje de $42000 \mathrm{~km}^{2}$, los investigadores del Observatorio de Medios encontraron en el anuncio del presidente Santos (26 de agosto de 2012) una oportunidad para analizar los contenidos de los discursos de los negociadores, la oposición, los medios de comunicación y las opiniones de los ciudadanos, recopilándolos primero y triangulándolos posteriormente para entender las dinámicas de esta negociación y establecer el papel de los actores señalados en el primer gran momento para la democracia colombiana en el siglo XXI.

\section{El plebiscito fue valorado como tema central de discusión pública}

La figura 6 muestra que en el $61 \%$ de los artículos el plebiscito fue tratado como tema central, asunto que fue el denominador común cuando el análisis se hizo para cada medio en particular, excepto en Semana y El Colombiano. Según se observa también en la figura 7 en Semana, sus articulistas siempre trataron el plebiscito como tema central de sus reflexiones (100 \%); y El Colombiano, cuando se refirió al plebiscito, lo hizo anteponiendo otros temas (58\%).

Desde la perspectiva del sexo del autor de la pieza de opinión (tabla 6), se midió también si el plebiscito era el tema central de la publicación, valoración en la que se halló mayor interés de las mujeres en tratar el plebiscito como tema único en sus columnas (69\%) y en los varones el interés del plebiscito como tema central fue un poco inferior $(61 \%)$. 
Figura 6. El plebiscito como tema central de la pieza de opinión

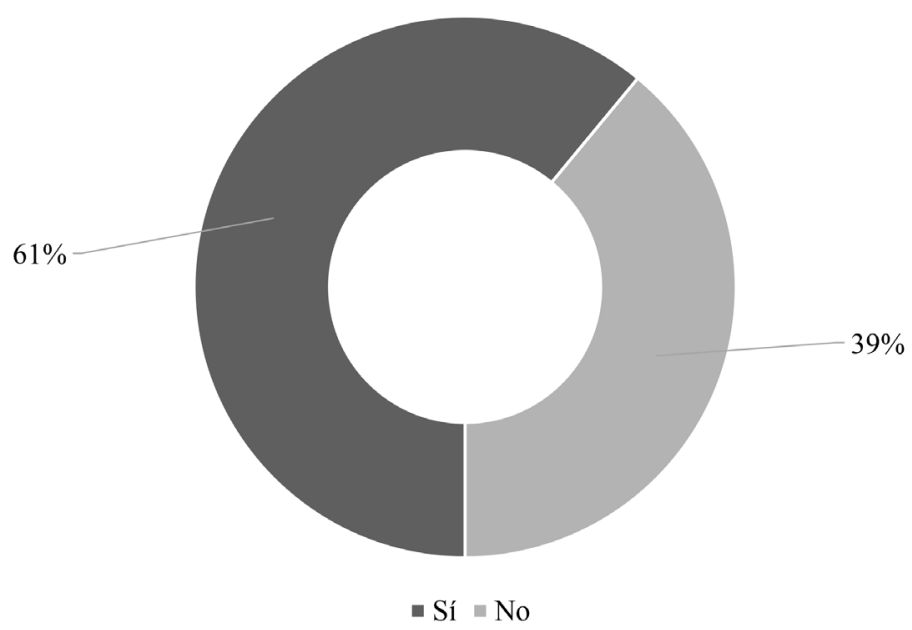

Fuente: elaboración propia.

\section{Figura 7. El plebiscito como tema central de la pieza de opinión según el medio de comunicación objeto de análisis}

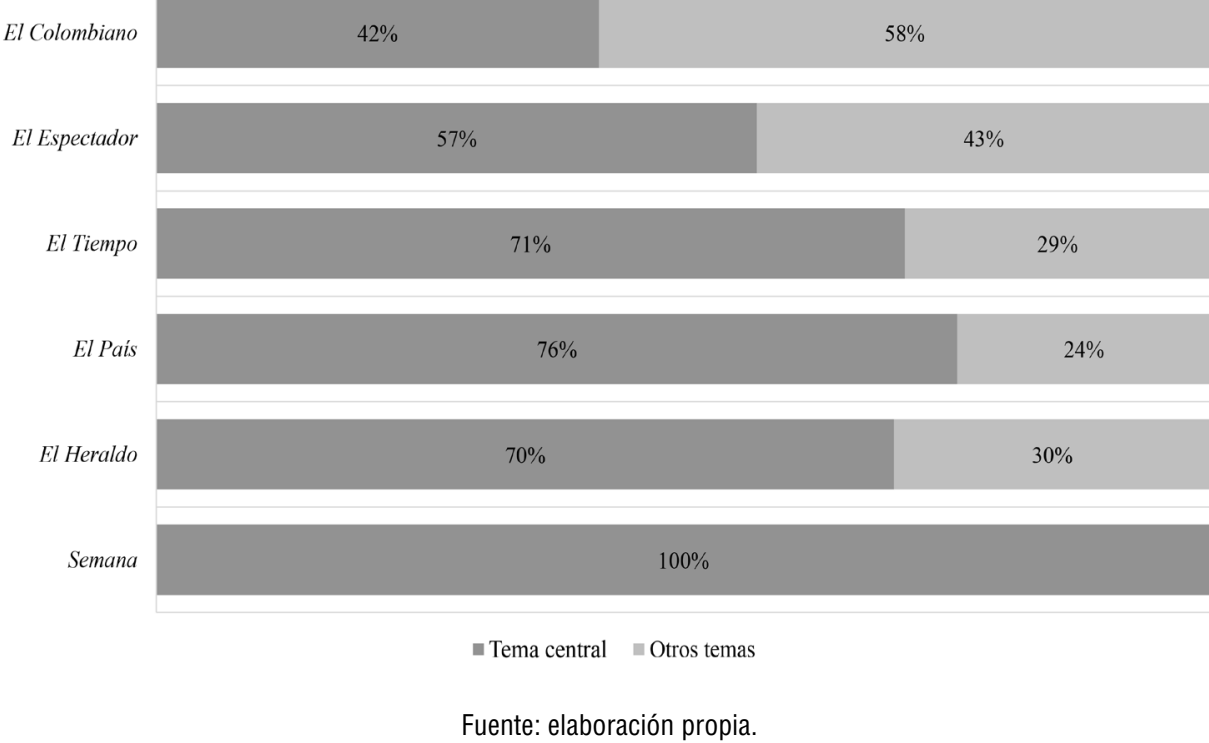




\section{Tabla 6. El plebiscito como tema central de la pieza de opinión según el sexo de su autor}

\begin{tabular}{|c|c|c|}
\hline Sexo & Tema central (\%) & Otros temas (\%) \\
\hline Mujer & 69 & 31 \\
\hline Varón & 61 & 39 \\
\hline
\end{tabular}

Fuente: elaboración propia.

\section{El plebiscito y temas asociados}

También se estudió la manera en que la opinión publicada relacionó el plebiscito con otros temas de la actualidad nacional (figura 8). Estos resultados asocian el tema, de manera lógica y esperada, con asuntos de política nacional (28\%). Pero llama la atención que en la segunda mayor frecuencia sea relacionado con el tema justicia ( $14 \%$ ), asunto que ha presentado el mayor grado de dificultad a la hora de su reglamentación en la legislatura del posacuerdo en el Congreso.

\section{Figura 8. Otros temas tratados por los articulistas relacionados con el plebiscito.}

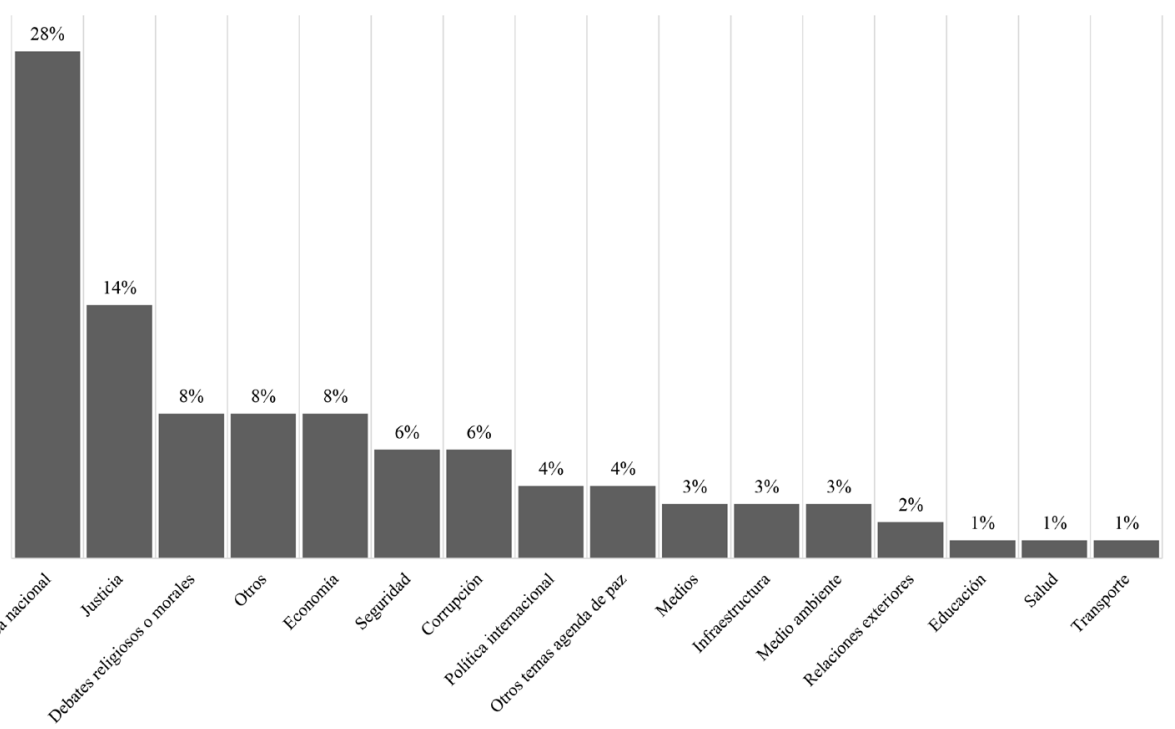

Fuente: elaboración propia. 
El estudio de esta variable desde la perspectiva de los medios de comunicación ofrece resultados similares, pero conviene hacer algunas precisiones.

El Colombiano asoció el plebiscito con la política nacional (25\%), con los debates religiosos y morales (14\%), con la economía (12\%) y, por último, con la justicia (11\%). Sobre el segundo tema, El Colombiano fue el periódico que mayor importancia otorgó a los debates religiosos y morales. Para la opinión publicada en El Espectador, el plebiscito tuvo relación directa con temas de política nacional (30\%) y justicia (22\%); temáticas que de manera parecida interesaron a la opinión expresada en El Tiempo: política nacional $(31 \%)$ y justicia $(11 \%)$. El País lo relacionó con la corrupción (17\%), la política nacional (17\%) y la justicia (13\%). Por último, para $E l$ Heraldo el plebiscito tuvo relación directa con temas como política nacional $(33 \%)$, seguridad (16\%) y justicia (16\%). No se presentan resultados de Semana porque en las columnas estudiadas se mantuvo el plebiscito como tema central (tabla 7).

\section{Tabla 7. Otros temas tratados por los articulistas relacionados con el plebiscito según los medios de comunicación observados}

\begin{tabular}{|c|c|c|c|c|c|}
\hline Tema/medio de comunicación & El Colombiano (\%) & ElEspectador (\%) & EITiempo (\%) & ElPaís (\%) & $\begin{array}{c}\text { El Heraldo } \\
(\%)\end{array}$ \\
\hline Política nacional & 25 & 30 & 31 & 17 & 33 \\
\hline Otros paz & 4 & 0 & 20 & 0 & 0 \\
\hline Justicia & 11 & 22 & 11 & 13 & 16 \\
\hline Política internacional & 4 & 2 & 7 & 7 & 8 \\
\hline Medio ambiente & 1 & 4 & 5 & 0 & 5 \\
\hline Corrupción & 4 & 9 & 5 & 17 & 3 \\
\hline Relaciones exteriores & 2 & 2 & 2 & 0 & 3 \\
\hline Seguridad & 4 & 7 & 2 & 7 & 16 \\
\hline Debates religiosos o morales & 14 & 6 & 2 & 3 & 0 \\
\hline Otros & 9 & 5 & 2 & 17 & 8 \\
\hline Educación & 1 & 2 & 0 & 7 & 0 \\
\hline Transporte & 1 & 1 & 0 & 0 & 0 \\
\hline Medios & 5 & 3 & 0 & 3 & 3 \\
\hline
\end{tabular}

Fuente: elaboración propia. 
En la tabla 8, se observa que las mujeres relacionaron el plebiscito con temas de política nacional (25\%), justicia (17\%), debates religiosos o morales y seguridad (11\%). Los varones plantearon la misma prioridad temática, pero con porcentajes diferentes: política nacional (25\%), justicia $(14 \%)$ y debates religiosos o morales (9\%).

\section{Tabla 8. Otros temas tratados por los articulistas relacionados con el plebiscito según el sexo del autor}

\begin{tabular}{|l|c|c|}
\hline \multicolumn{1}{|c|}{ Tema/medio de comunicación } & Mujer (\%) & Varón (\%) \\
\hline Política nacional & 25 & 25 \\
\hline Otros paz & 6 & 4 \\
\hline Justicia & 17 & 14 \\
\hline Economía & 3 & 8 \\
\hline Política internacional & 0 & 5 \\
\hline Medio ambiente & 3 & 3 \\
\hline Corrupción & 6 & 7 \\
\hline Salud & 0 & 3 \\
\hline Infraestructura & 6 & 2 \\
\hline Relaciones exteriores & 0 & 5 \\
\hline Seguridad & 11 & 9 \\
\hline Debates religiosos o morales & 11 & 8 \\
\hline Otros & 9 & 1 \\
\hline Educación & 0 & 3 \\
\hline Transporte & 0 & 2 \\
\hline Medios & 3 & 3 \\
\hline
\end{tabular}

Fuente: elaboración propia.

\section{La posición asumida por la opinión publicada frente al Sí 0 al No en el plebiscito}

Después de caracterizar la opinión publicada se identificó, desde el análisis de los contenidos de las 466 piezas que componen el universo de la presente investigación, la postura de los artículos a favor de cualquiera de las dos posibilidades ofrecidas por la pregunta del plebiscito; en este caso, en el $54 \%$ de los artículos se puede apreciar una inclinación hacia cualquiera de los polos propuestos. 
En la figura 9, se observa que, de las 235 piezas de opinión en las que se apreció una postura, en 216 (85 \%) la posición fue por el Sí, en 35 piezas (14\%) por el No y el $1 \%$ argumentó a favor de la abstención. Estos son resultados de las cifras relativas del presente estudio; pero, cuando se observan las cifras absolutas, esas 216 piezas en las que sus autores invitaron a votar por el Sí, alcanzan el $46 \%$ del total de piezas publicadas sobre el plebiscito, en tanto que el No solo llegó al 7,5 \% del universo de piezas estudiadas.

La investigación del Observatorio de Medios midió también la postura de los medios escritos a favor del Sí o del No durante los cuarenta días que antecedieron al plebiscito.

\section{Figura 9. Cuando se toma postura, ¿cuál es la posición de los articulistas frente al plebsicito?}

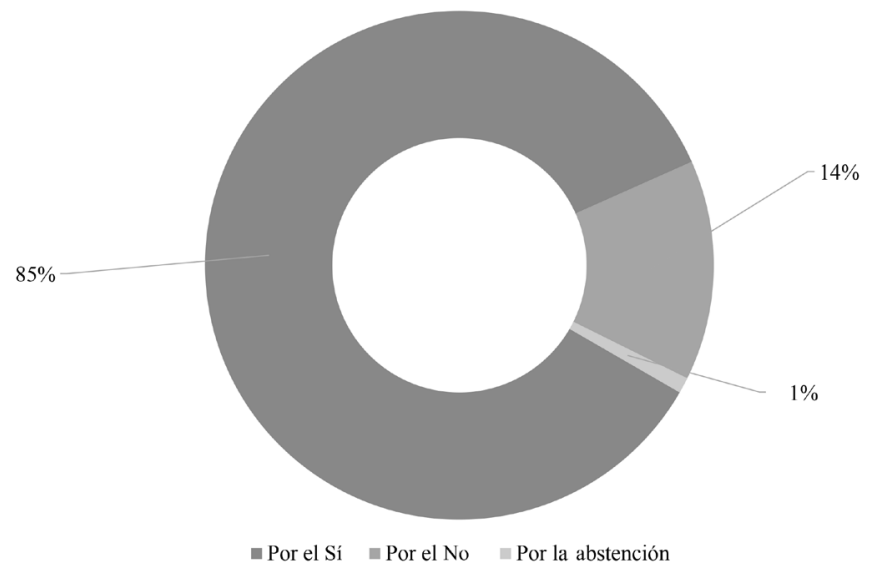

Fuente: elaboración propia.

Todos los columnistas de Semana le apostaron al Sí (100\%), seguido de los columnistas y editorialistas de El País de Cali (96\%), El Heraldo de Barranquilla (94\%), El Espectador (94\%) y El Tiempo (91\%), ambos de Bogotá y considerados como diarios de circulación nacional. El Colombiano de Medellín, contrario a sus homólogos de las otras ciudades señaladas, fue el que mayor número de piezas publicó con posiciones a favor del No en el plebiscito, un total de 25 que alcanzaron un $35 \%$ del total de los artículos en los cuales se tomó una posición frente al tema (figura 10). 


\section{Figura 10. Cuando se toma postura, ¿cuál es la posición frente al plebiscito según el medio de comunicación?}

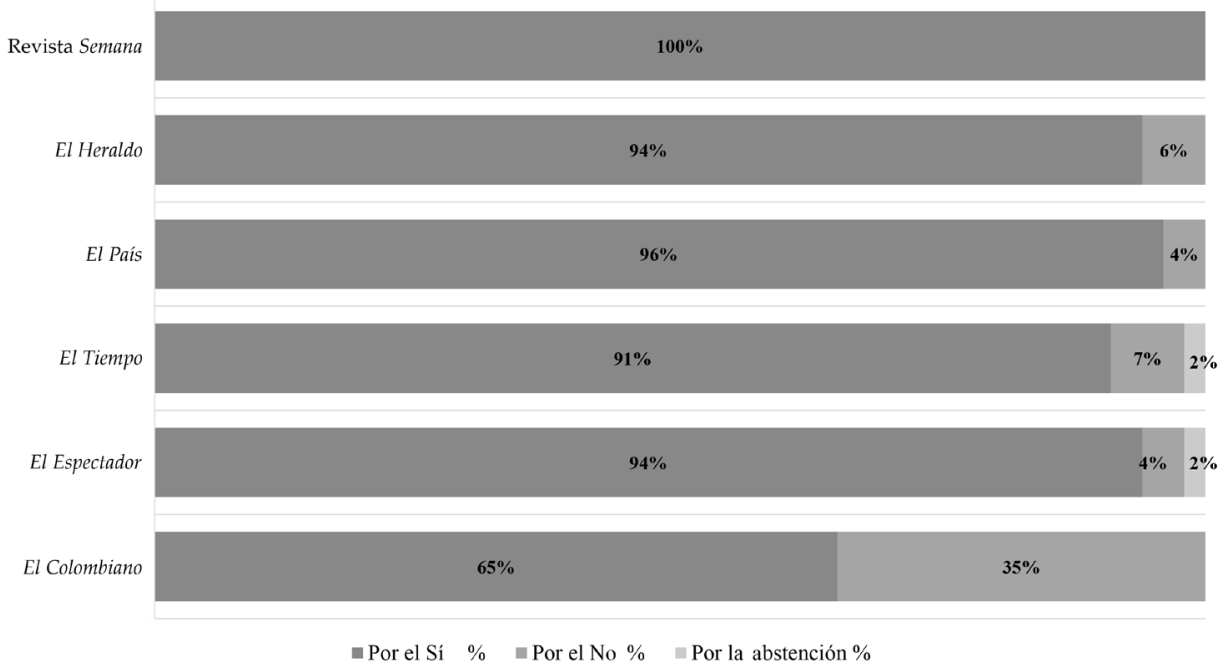

Fuente: elaboración propia.

Para ilustrar los resultados señalados, la columnista de Semana, María Jimena Duzán, en uno de sus artículos tituló "Un voto por el futuro" e indicó que "lo acordado en La Habana nos da la oportunidad de salir de la barbarie, y nos permite empezar a reconstruir el país desde el respeto, la tolerancia y la inclusión” (Duzán, 2016). En El País de Cali, Luis Felipe Gómez Restrepo explicó su "Razón de un sí" con la reflexión: "El sentido profundo de construcción de humanidad en nuestro país debe ser el motivo que nos anime a hacer una valoración de lo acordado" (Gómez Restrepo, 2016). Otro argumento a favor del Sí se pudo leer en El Heraldo, en que Alberto Martínez bajo el título "Lo bueno del sî" recordó: "La recomendación de los expertos es que volvamos a entrenar nuestro cerebro para acostumbrarlo a expresiones amables como amor, paz y sî" (Martínez, 2016). Héctor Abad Faciolince en El Espectador acudió a "Ritmo de rap por el sî" y de una manera distinta invitó a votar por el sí:

Hoy es un día de fiesta / ve a votar sin hacer siesta, / hoy sabremos la respuesta / si el sí gana la propuesta. / Hoy no te pegues la perra, / no es un domingo de guerra, / puedes venir a tu tierra, / hoy empieza la posguerra. 
En El Colombiano, el propio presidente Juan Manuel Santos invitó a los colombianos a votar por el Sí:

Ha llegado el momento de dejar atrás la confrontación y la polarización. No para reemplazarla por la unanimidad, sino para acordar, con respeto por las diferencias, la agenda de trabajo en la que todos podemos aportar, porque la paz la construiremos entre todos. El pueblo colombiano tiene la fortaleza, la determinación, la generosidad para lograrlo. Contaremos con el apoyo de países amigos y de la comunidad internacional, que ven con admiración la capacidad transformadora de nuestra nación. (Santos, 2016)

Unas cuantas voces por el No se oyeron en algunos de los diarios estudiados, pero El Colombiano de Medellín tomó la delantera con piezas de opinión tales como la publicada el mismo día del plebiscito por Rafael Nieto Loaiza, quien concluyó su columna en estos términos: "Porque creo que no hay cómo pagar este acuerdo, porque es manifiestamente injusto con los inocentes, porque no pone fin al conflicto sino que es germen de nuevas violencias, y porque premia el crimen, voto NO" (Nieto, 2016).

Cabe también hacer un análisis de la posición de los medios desde sus editoriales; de los seis estudiados, se excluye Semana, medio que tradicionalmente no publica editoriales; de los cinco restantes, cuatro tomaron posturas claras a favor del Sí al plebiscito.

El Tiempo, en su editorial del domingo 2 de octubre de 2016, tituló "La razones de un sí, y en líneas posteriores manifestó: "El Tiempo recomienda a sus lectores que acudan hoy a las urnas la opción del sí en el tarjetón”. Por su parte, El Espectador, en su editorial de la misma fecha, tituló “Es el momento de decir sí”, e indicó que "apostar con el sí es abrir una puerta de nuevas posibilidades para que esta nación pueda comenzar a cicatrizar sus heridas" (El Espectador, 2016c).

El Heraldo hizo lo propio; el viernes 30 de septiembre tituló su editorial "Un sí vigilante" y manifestó que "en la actual coyuntura histórica, y colocados los diversos argumentos en una balanza, consideramos que un 'sí en el plebiscito del domingo es más útil que un 'no' para nuestro proyecto 
común de país" (El Heraldo, 2016c). Un poco más sutil fue la posición de El País, medio que desde su editorial del 2 de octubre titulado "La hora de la verdad" explicó: "Es la hora de la verdad porque es la hora de decidir sobre algo en lo cual se compromete el futuro del país con las soluciones pacíficas a sus diferencias" (El País, 2016a).

El Colombiano fijó una posición neutra al titular en la misma fecha en su editorial “Colombia, entre el sí y el no", e invitó "al país a que vote — no estamos de acuerdo con la abstención - con amor, transparencia, coherencia, serenidad, a conciencia y desde la libertad" (El Colombiano, 2016c).

La posición asumida según el sexo marca una pequeña diferencia; las mujeres que publican sus opiniones en la prensa presentaron mayor inclinación a favor del Sí ( $89 \%$ ) que los hombres (84\%) (tabla 9).

\section{Tabla 9. Cuando se toma postura, ¿cuál es la posición del articulista frente al plebiscito según el sexo del autor?}

\begin{tabular}{|c|c|c|c|}
\hline Sexo/postura & Por el Sí (\%) & Por el No (\%) & Por la abstención (\%) \\
\hline Femenino & 89 & 11 & 0 \\
\hline Masculino & 84 & 15 & 1 \\
\hline
\end{tabular}

Fuente: elaboración propia.

Lo que es preciso manifestar con los resultados de estas variables medidas es que los ciudadanos fueron en contravía de lo sugerido por la opinión publicada respecto del plebiscito del 2 de octubre de 2016 en Colombia, convocado por el Gobierno colombiano para refrendar los acuerdos de paz con las FARC. En el universo analizado (466 piezas de opinión, publicadas durante los cuarenta días previos al plebiscito), se observó una inclinación mayoritaria en la opinión publicada hacia el Sí, contrario a lo que ocurrió en los puestos de votación, a los que el 62,57 \% ya mencionado de los colombianos no asistió; del porcentaje restante, el 18,42\% votaron por el No y el 18,27 \% por el Sí, victoria de una minoritaria mayoría (Registraduría Nacional del Estado Civil, 2016). 


\section{Argumentos, valores y valoraciones de la opinión publicada sobre el plebiscito}

\section{Frames usados por la opinión publicada para soportar la argumentación}

En el análisis descriptivo que se desarrolla, se consideró de suma importancia el tipo de argumentos usados por los columnistas y los líderes de opinión para expresar su posición frente al plebiscito. Para ello, se optó por una clasificación básica que permitiera conocer si esos argumentos estaban sustentados en los hechos que vivía el país (lo episódico) o si lo estaban en cifras, datos, referencias y citas (argumentos temáticos) (Aaroe, 2011, p. 209).

Como se aprecia en la figura 10, la opinión publicada sobre el plebiscito durante los cuarenta días previos a su realización fue una opinión basada en la coyuntura informativa: argumentos episódicos con un $63 \%$, en los que se privilegió la discusión política sobre un acuerdo que no fue comunicado de manera conveniente, y escasearon las explicaciones: argumentos temáticos con un $37 \%$.

\section{Figura 11. Tipo de argumentación usada por la opinión publicada sobre el plebiscito}

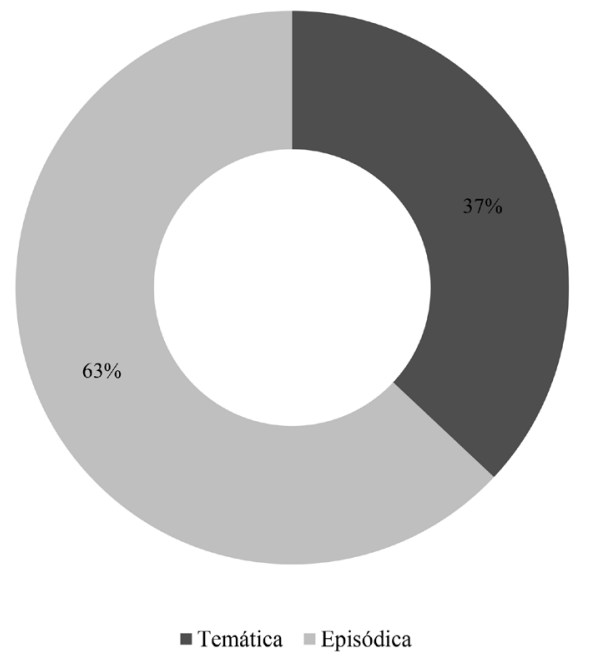

Fuente: elaboración propia. 
Esta medición se hizo para los periódicos y la revista, y de ella se derivaron los siguientes resultados (tabla 10).

\section{Tabla 10. Tipo de argumentación usada por la opinión publicada para respaldar sus posturas frente al plebiscito según los medios de comunicación}

\begin{tabular}{|l|c|c|}
\hline \multicolumn{1}{|c|}{ Medio } & Temática & Episódica \\
\hline El Colombiano & 30 & 70 \\
\hline El Espectador & 34 & 66 \\
\hline El Tiempo & 56 & 44 \\
\hline El País & 10 & 90 \\
\hline El Heraldo & 51 & 49 \\
\hline Semana & 100 & 0 \\
\hline
\end{tabular}

Fuente: elaboración propia.

Los columnistas de Semana fueron quienes más se interesaron en argumentar temáticamente su postura frente al plebiscito (100\%), seguidos de los columnistas y editorialistas de El Tiempo (56\%) y El Heraldo (51\%), mientras que El Colombiano (70 \%) y El Espectador (66\%) privilegiaron la argumentación episódica.

\section{Valores usados para la argumentación de la opinión publicada sobre el plebiscito}

Los investigadores del Observatorio de Medios analizaron los argumentos esgrimidos por la opinión publicada y los asociaron con valores expresados en las piezas de opinión. Allí se obtuvieron los siguientes resultados.

La tabla 11 indica que para la opinión publicada el plebiscito estuvo asociado, principalmente, con valores políticos (35\%) y valores sociales (29\%), seguidos de valores culturales (14\%), jurídicos (12\%), económi$\cos (8 \%)$ y religiosos $(2 \%)$. Esta medición se hizo también según los medios (tabla 11). 


\section{Tabla 11. Valores que soportaron la argumentación de la opinión publicada sobre el plebiscito}

\begin{tabular}{|l|c|c|}
\hline \multicolumn{1}{|c|}{ Valores } & Frecuencia & Porcentaje (\%) \\
\hline Políticos & 340 & 35 \\
\hline Sociales & 278 & 29 \\
\hline Culturales & 132 & 14 \\
\hline Jurídicos & 113 & 12 \\
\hline Económicos & 75 & 8 \\
\hline Religiosos & 24 & 2 \\
\hline Total & $\mathbf{9 6 2}$ & $\mathbf{1 0 0}$ \\
\hline
\end{tabular}

Fuente: elaboración propia.

Los resultados obtenidos en la medición de esta variable y contenidos en la tabla 12 nos permiten concluir que El Colombiano privilegió la argumentación sustentada en valores sociales, mientras que los demás medios escritos (El Espectador, El Tiempo, El País, El Heraldo y Semana) sustentaron sus argumentos en valores políticos.

\section{Tabla 12. Valores que soportaron la argumentación de la opinión publicada sobre el plebiscito según los medios de comunicación}

\begin{tabular}{|c|c|c|c|c|c|c|c|c|c|c|c|c|c|c|}
\hline \multirow{2}{*}{$\begin{array}{c}\text { Medios/ } \\
\text { Valores }\end{array}$} & \multicolumn{2}{|c|}{ Políticos } & \multicolumn{2}{|c|}{ Sociales } & \multicolumn{2}{|c|}{ Culturales } & \multicolumn{2}{|c|}{ Jurídicos } & \multicolumn{2}{|c|}{ Económicos } & \multicolumn{2}{|c|}{ Religiosos } & \multicolumn{2}{|c|}{ Total } \\
\hline & $\mathbf{F}$ & $\%$ & $\mathbf{F}$ & $\%$ & $\mathbf{F}$ & $\%$ & $\mathbf{F}$ & $\%$ & $\mathbf{F}$ & $\%$ & $\mathbf{F}$ & $\%$ & $\mathbf{F}$ & $\%$ \\
\hline El Colombiano & 72 & 30 & 76 & 32 & 33 & 14 & 26 & 11 & 24 & 10 & 6 & 3 & 237 & 100 \\
\hline El Espectador & 83 & 37 & 62 & 28 & 31 & 14 & 26 & 12 & 13 & 6 & 8 & 3 & 223 & 100 \\
\hline El Tiempo & 82 & 38 & 61 & 29 & 30 & 14 & 20 & 9 & 17 & 8 & 3 & 2 & 213 & 100 \\
\hline El País & 53 & 48 & 33 & 30 & 6 & 5 & 11 & 10 & 4 & 4 & 4 & 3 & 111 & 100 \\
\hline El Heraldo & 44 & 27 & 42 & 26 & 31 & 19 & 27 & 17 & 15 & 9 & 3 & 2 & 162 & 100 \\
\hline Semana & 6 & 36 & 4 & 26 & 1 & 6 & 3 & 19 & 2 & 13 & 0 & 0 & 16 & 100 \\
\hline Total & 340 & 35 & 278 & 29 & 132 & 14 & 113 & 12 & 75 & 8 & 24 & 2 & 962 & 100 \\
\hline
\end{tabular}




\section{Valoración a los actores de la negociación en la opinión publicada}

La investigación del Observatorio de Medios con el apoyo de Siglo Data MMI revisó la postura de los columnistas y editorialistas acerca del papel cumplido por los protagonistas de la negociación de paz en La Habana, a través del análisis de contenido de las 466 piezas publicadas en las páginas de opinión de los periódicos y la revista durante los cuarenta días previos a la realización del plebiscito el 2 de octubre de 2016. Se determinó únicamente consignar la información cuando se observase en el contenido de la pieza alguna valoración positiva a cualquiera de los actores de la negociación.

En términos generales, se advierte que en un mínimo porcentaje los columnistas expresaron valoraciones positivas; la tendencia fue a mantener neutralidad. Solo en un $15 \%$ (69) de las piezas de opinión sus autores manifestaron valoraciones positivas sobre los actores del proceso de negociación; en estos resultados, llevó la delantera el Gobierno con un $6 \%$, seguido de la oposición con un $5 \%$ y, por último, las FARC con un $4 \%$, datos que se observan en la tabla 13. Estos resultados están muy equilibrados y no se puede atribuir relevancia de alguno de los actores calificados.

\section{Tabla 13. Valoración positiva a los actores del proceso de negociación por parte de la opinión publicada}

\begin{tabular}{|l|c|c|}
\hline \multicolumn{1}{|c|}{ Valoración positiva } & Frecuencia & Porcentaje (\%) \\
\hline Gobierno & 29 & 6 \\
\hline Oposición & 22 & 5 \\
\hline FARC & 18 & 4 \\
\hline Total & $\mathbf{6 9}$ & $\mathbf{1 5}$ \\
\hline
\end{tabular}

Nota: Base: 466 piezas de opinión analizadas.

Fuente: elaboración propia.

Según los datos obtenidos en el estudio y presentados en la tabla 14, el medio que hizo más valoraciones positivas sobre el Gobierno fue $\mathrm{El} \mathrm{He-}$ raldo: 10, para un $34 \%$; seguido de El Tiempo: 8, para el $28 \%$. El Colombiano fue el periódico que mayor número de valoraciones positivas hizo 
sobre la oposición con 16, para un $73 \%$. Por último, El Heraldo fue el medio que mayor número de valoraciones positivas hizo sobre las FARC con 8 (44\%), seguido de El País con 5, para un $28 \%$.

\section{Tabla 14. Valoración positiva de los actores del proceso de negociación por parte de la opinión publicada según los medios de comunicación}

\begin{tabular}{|l|c|c|c|c|c|c|}
\hline \multirow{2}{*}{ Medio } & \multicolumn{2}{|c|}{$\begin{array}{c}\text { Valoración positiva al } \\
\text { Gobierno }\end{array}$} & \multicolumn{2}{c|}{$\begin{array}{c}\text { Valoración positiva a la } \\
\text { oposición }\end{array}$} & \multicolumn{2}{c|}{$\begin{array}{c}\text { Valoración positiva a las } \\
\text { FARC }\end{array}$} \\
\cline { 2 - 7 } & F & $\mathbf{9}$ & F & \% & F & \% \\
\hline El Colombiano & 5 & 17 & 16 & 73 & 1 & 6 \\
\hline El Espectador & 2 & 7 & 1 & 4 & 2 & 11 \\
\hline El Tiempo & 8 & 28 & 0 & 0 & 2 & 11 \\
\hline El País & 4 & 14 & 1 & 4 & 5 & 28 \\
\hline El Heraldo & 10 & 34 & 4 & 19 & 8 & 44 \\
\hline Semana & 0 & 0 & 0 & 0 & 0 & 0 \\
\hline Total & $\mathbf{2 9}$ & $\mathbf{1 0 0}$ & $\mathbf{2 2}$ & $\mathbf{1 0 0}$ & $\mathbf{1 8}$ & $\mathbf{1 0 0}$ \\
\hline
\end{tabular}

\section{Las palabras, los personajes y las instituciones más mencionados por la opinión publicada sobre el plebiscito}

Este proceso de análisis de los contenidos de las piezas de opinión sobre el plebiscito del 2 de octubre de 2016 con el que el Gobierno nacional pretendió refrendar los acuerdos de paz con las FARC quiso medir también las palabras más usadas por los editorialistas y columnistas en sus escritos, para tratar de inferir desde allí las categorías argumentativas más relevantes. El universo de análisis (466 piezas) se sometió a los contadores de palabras y se presentan aquí como resultados todas aquellas que superaron el $1 \%$ de uso (no se tienen en cuenta los nombres de personas e instituciones, mediciones que se hicieron aparte).

En los resultados reseñados, primero, aparecen con mayor frecuencia y de manera lógica las palabras "Colombia” (147 veces), "acuerdos" (146 
veces) y "paz" (123 veces), categorías que ofrecen el contexto adecuado a los lectores de la opinión publicada; segundo, se leen otras palabras que al parecer explican los procesos que se cumplen, como "plebiscito" (60 veces), "guerra” (54 veces), "Gobierno" (40 veces), "política” (39 veces) y “voto" (36 veces); tercero, palabras que fijan posiciones respecto del fenómeno que se comenta, como "justicia” ( 22 veces), "conflicto" ( 20 veces), "Estado" (20 veces), "todos” (19 veces), "violencia” (18 veces), "final” (16 veces) y "años” (15 veces); y, por último, palabras con menor frecuencia en la argumentación, como "víctimas" (13 veces) y "proceso" (12 veces) (tabla 15).

\section{Tabla 15. Palabras más usadas por la opinión publicada sobre el plebiscito del 2 de octubre de 2016 en Colombia}

\begin{tabular}{|l|c|c|}
\hline \multicolumn{1}{|c|}{ Palabra } & Frecuencia & Porcentaje (\%) \\
\hline Colombia & 147 & 15 \\
\hline Acuerdos & 146 & 15 \\
\hline Paz & 123 & 13 \\
\hline Plebiscito & 60 & 6 \\
\hline Guerra & 54 & 6 \\
\hline Gobierno & 40 & 4 \\
\hline Política & 39 & 4 \\
\hline Voto & 36 & 4 \\
\hline Justicia & 22 & 2 \\
\hline Conflicto & 20 & 2 \\
\hline Estado & 20 & 2 \\
\hline Todos & 19 & 2 \\
\hline Violencia & 18 & 2 \\
\hline Final & 16 & 2 \\
\hline Años & 13 & 2 \\
\hline Víctimas & 12 & 1 \\
\hline Proceso & 13 & \\
\hline & & \\
\hline
\end{tabular}

Fuente: elaboración propia. 
Como se anunció antes, se presentan a continuación los resultados de la medición respecto de los nombres de personas más mencionadas en las piezas de opinión publicadas durante los cuarenta días previos al plebiscito del 2 de octubre de 2016 en Colombia. Se mencionan los nombres de acuerdo con el uso que de ellos hicieron en las piezas de opinión (algunos son apodos o alias). Se expresan en el conteo todas aquellas personas que fueron nombradas al menos en el $1 \%$ del total de menciones (tabla 16).

\section{Tabla 16. Personas más mencionadas por la opinión publicada sobre el plebiscito del 2 de octubre de 2016 en Colombia}

\begin{tabular}{|l|l|l|}
\hline \multicolumn{1}{|c|}{ Persona } & Frecuencia & Porcentaje (\%) \\
\hline Juan Manuel Santos & 135 & 19 \\
\hline Álvaro Uribe Vélez & 100 & 14 \\
\hline Humberto de la Calle & 48 & 7 \\
\hline “Timochenko" & 41 & 6 \\
\hline Alejandro Ordóñez & 27 & 4 \\
\hline Andrés Pastrana & 17 & 2 \\
\hline Germán Vargas Lleras & 13 & 2 \\
\hline Sergio Jaramillo & 12 & 2 \\
\hline César Gaviria & 11 & 2 \\
\hline Nicolás Maduro & 10 & 1 \\
\hline Gustavo Rojas Pinilla & 8 & 1 \\
\hline Belisario Betancur & 7 & 1 \\
\hline Papa Francisco & 7 & 1 \\
\hline Paloma Valencia & 7 & 1 \\
\hline Óscar Iván Zuluaga & 7 & 1 \\
\hline Jorge Eliécer Gaitán & 7 & 1 \\
\hline María Isabel Rueda & 6 & 1 \\
\hline Rafael Pardo & 6 & 1 \\
\hline Barack Obama & 6 & 1 \\
\hline María Fernanda Cabal & 6 & 1 \\
\hline General Jorge Enrique Mora & 6 & 1 \\
\hline "Iván Márquez" & 6 & 1 \\
\hline Gustavo Petro & 6 & 1 \\
\hline Carlos Holmes Trujillo & & 1 \\
\hline & 6 & 1 \\
\hline
\end{tabular}




\begin{tabular}{|l|l|l|}
\hline \multicolumn{1}{|c|}{ Persona } & Frecuencia & Porcentaje (\%) \\
\hline Luis Carlos Villegas & 5 & 1 \\
\hline "Manuel Marulanda Vélez" & 5 & 1 \\
\hline "Jesús Santrich" & 5 & 1 \\
\hline Vivianne Morales & 4 & 1 \\
\hline General Alberto Mejía & 4 & 1 \\
\hline "Romaña" & 4 & 1 \\
\hline Juan Carlos Henao & 4 & 1 \\
\hline Hugo Chávez & 4 & 1 \\
\hline Laureano Gómez & 4 & 1 \\
\hline Virgilio Barco & 4 & 1 \\
\hline Ban Ki Moon & 4 & 1 \\
\hline Antonio Navarro Wolf & 4 & 1 \\
\hline
\end{tabular}

Fuente: elaboración propia.

En primer lugar, es significativo que después del presidente Juan Manuel Santos (135 veces) aparezca el senador Álvaro Uribe Vélez (100 veces), evidencia clara del protagonismo de los sectores de la oposición al proceso de paz; en segundo lugar, los nombres del negociador del Gobierno en La Habana Humberto de la Calle (48 veces) y del jefe de las FARC, Rodrigo Londoño Echeverri, alias "Timochenko" (41 ocasiones); en tercer lugar, algunas figuras de la coyuntura política colombiana, como Alejandro Ordóñez (27 veces), Andrés Pastrana (17 veces), Germán Vargas (13 veces) y César Gaviria (11 veces); y en cuarto lugar, con una menor frecuencia, figuras de la historia política colombiana que en su momento protagonizaron hechos clave en plebiscitos o procesos de paz, como Gustavo Rojas Pinilla, Belisario Betancur y Jorge Eliécer Gaitán. También en este mismo tipo de frecuencia son registrados otros nombres de políticos colombianos que tuvieron alguna incidencia en el proceso antes del plebiscito, como Óscar Iván Zuluaga, Paloma Valencia, Rafael Pardo, María Fernanda Cabal, Gustavo Petro, Carlos Holmes Trujillo y Vivianne Morales. Asimismo, algunos jefes militares activos y negociadores de las FARC en La Habana, como los generales Jorge Enrique Mora (retirado) y Alberto Mejía (comandante del Ejército) y los miembros de las FARC: Luciano Marín Arango, alias "Iván Márquez"; Zeuxis Pausias Hernández Solarte, 
alias "Jesús Santrich”; y Henry Castellanos Garza, alias "Romaña”. Por último, es importante registrar la mención a figuras de carácter internacional como Nicolás Maduro, el papa Francisco, Barack Obama, Hugo Chávez y Ban Ki Moon.

Además, se hizo el conteo de las instituciones más mencionadas por los columnistas y editorialistas de los principales medios escritos del país durante los cuarenta días previos a la realización del plebiscito refrendatorio. En las 466 piezas, se encontraron mencionadas las siguientes instituciones (se relacionan aquellas que obtuvieron al menos el $1 \%$ de las citas) (tabla 17).

\section{Tabla 17. Instituciones más mencionadas por la opinión publicada sobre el plebiscito del $\mathbf{2}$ de octubre de 2016 en Colombia}

\begin{tabular}{|c|c|c|}
\hline Institución & Frecuencia & Porcentaje (\%) \\
\hline FARC & 201 & 20 \\
\hline Gobierno & 134 & 13 \\
\hline Congreso de la República & 53 & 5 \\
\hline Estado & 43 & 4 \\
\hline Corte Constitucional & 33 & 3 \\
\hline Presidencia de la República & 30 & 3 \\
\hline Organización de las Naciones Unidas & 24 & 2 \\
\hline ELN & 19 & 2 \\
\hline Centro Democrático & 17 & 2 \\
\hline Fuerzas Armadas & 15 & 2 \\
\hline Ejército & 14 & 2 \\
\hline Senado & 12 & 1 \\
\hline Consejo de Estado & 12 & 1 \\
\hline Consejo Nacional Electoral & 10 & 1 \\
\hline Corte Suprema de Justicia & 9 & 1 \\
\hline Iglesia católica & 7 & 1 \\
\hline Unión Europea & 7 & 1 \\
\hline Registraduría Nacional del Estado Civil & 7 & 1 \\
\hline Corte Penal Internacional & 6 & 1 \\
\hline Procuraduría General de la Nación & 6 & 1 \\
\hline El Espectador & 6 & 1 \\
\hline
\end{tabular}




\begin{tabular}{|l|c|c|}
\hline M-19 & 6 & 1 \\
\hline Tribunal de Paz & 6 & 1 \\
\hline Partido Liberal & 6 & 1 \\
\hline Bacrim & 5 & 1 \\
\hline Cambio Radical & 5 & 1 \\
\hline El Colombiano & 5 & 1 \\
\hline Fiscalía General de la Nación & 5 & 1 \\
\hline Ministerio de Hacienda & 5 & 1 \\
\hline Unión Patriótica & 5 & 1 \\
\hline
\end{tabular}

Fuente: elaboración propia.

Primero, por el alto número de menciones, aparecen los actores del proceso de negociación en La Habana: el Estado colombiano (aquí se agrupan las menciones a Gobierno, Estado, Presidencia de la República y Ministerio de Hacienda), con 212 menciones, seguido de las FARC con 201 menciones. Segundo, aparecen instituciones representativas de los otros poderes del Estado, como Congreso y Senado, con 65 menciones; Corte Constitucional, Consejo de Estado, Corte Suprema de Justicia y Fiscalía General de la Nación, con 59 menciones; algunos organismos internacionales que tienen alta relación con el proceso de paz, como la Organización de las Naciones Unidas (ONU), la Unión Europea (UE) y la Corte Penal Internacional, con 37 referencias directas; algunos partidos políticos, como el Centro Democrático, el Partido Liberal, Cambio Radical y la Unión Patriótica, con 33 menciones; organismos de seguridad del Estado, como las Fuerzas Armadas y el Ejército, con 29 menciones; otros órganos de control estatal, como el Consejo Nacional Electoral, la Registraduría Nacional del Estado Civil y la Procuraduría General de la Nación, con 23 menciones; fueron referidos también dos medios de comunicación, El Espectador y El Colombiano, con citas de autorreferenciación 11 veces, y la Iglesia católica fue mencionada en 7 oportunidades.

\section{Conclusiones}

La prensa colombiana otorgó al plebiscito el grado de importancia que merece un acontecimiento de carácter histórico, según se deriva de los indicadores propuestos en esta investigación, como cantidad de artículos de 
opinión publicados durante el periodo de análisis (466), titulación en primera página de las piezas de opinión publicadas (33 artículos en los cuarenta días de observación), alto porcentaje (para el periodo analizado) de editoriales destinados a comentar de manera directa e indirecta asuntos relacionados con este mecanismo de participación democrática (5\%) y cantidad de voces que desde diferentes orillas ideológicas argumentaron a favor del Sí o del No e invitaron a los electores a ejercer su derecho en tan trascendental hecho a través de columnas y editoriales. No obstante, se evidenció una escasa participación de las mujeres en las secciones de opinión de los diarios de referencia ( $8 \%$ ), frente al espacio obtenido por las voces masculinas (92\%), fenómeno que muestra —al menos - un gran desequilibrio en la discusión pública de un tema en el que todos tienen algo que decir.

En consonancia con el nivel de importancia otorgado por la prensa nacional al plebiscito, se observó que, en la mayoría de las piezas publicadas, este fue asumido como el tema central, conducta de Semana y El País, El Heraldo, El Tiempo y El Espectador, excepto de El Colombiano que priorizó otros, aunque asociados al mecanismo refrendatorio. Es preciso señalar que la opinión publicada entendió el plebiscito como un tema relacionado prioritariamente con la política nacional (28\%), seguido de la justicia (14\%), los debates religiosos y morales ( $8 \%$ ) y la economía ( $8 \%$ ). El primero resulta normal porque se entiende el plebiscito como un mecanismo de participación en política para el constituyente primario; el segundo, justicia, se presta para interpretaciones contradictorias, podría entenderse en sentido positivo, pero podría leerse también en sentido negativo, injusticia, asunto que debe investigarse mucho más a fondo y que queda como un debe para posteriores estudios.

La prensa de referencia en un $54 \%$ de los artículos publicados sobre el plebiscito tomó una posición (a favor del Sí o a favor del No), y cuando así se evidenció, la posición adoptada fue a favor del Sí (en 216 piezas). Cuando el medio asumió una posición editorial, lo hizo de manera mayoritaria a favor del Sí (El Tiempo, El Espectador, El País y El Heraldo), excepto El Colombiano, que no asumió postura desde sus editoriales, y 
Semana que no publica editoriales; sin embargo, todos sus columnistas respaldaron el Sí. Esta postura de editorialistas y columnistas no coincidió con lo expresado por los ciudadanos en las urnas, quienes privilegiaron el No a la pregunta de la convocatoria, y lleva a un análisis preliminar que pone de relieve "la inocuidad o la irrelevancia de las consignas editoriales” (Amón, 2016).

Ligada a las anteriores, otra conclusión importante tiene que ver con la argumentación de los articulistas de la prensa colombiana sobre un tema tan complejo y, a la vez, tan sensible para la vida democrática futura. Tal vez este fue el gran vacío; como se había señalado, las campañas del Sí y del No simplificaron los argumentos, también lo hicieron los editorialistas y los columnistas quienes se dejaron llevar por la premura y prefirieron lo emocional a lo racional, afirmación que se evidencia en la medición del tipo de frame usado; el $63 \%$ de las piezas de opinión publicadas por los seis medios analizados acudieron al frame episódico en el cual se sustentan los argumentos según las coyunturas informativas y no el análisis soportado en investigación, cifras, citas, características propias de los frames temáticos.

La opinión publicada sobre el plebiscito fue asociada principalmente a valores políticos $(35 \%)$ y valores sociales $(29 \%)$, seguidos de valores culturales (14\%), jurídicos (12\%), económicos $(8 \%)$ y religiosos (2\%); resultados que llaman la atención porque parecieran indicar que la principal preocupación de los columnistas y editorialistas respecto del proceso de paz y su futuro es de orden político, en primera instancia, y solo en segunda instancia, un asunto de tipo social.

La medición de la frecuencia de las palabras más usadas en los textos de opinión publicados por la prensa colombiana sobre el plebiscito muestra, primero, el uso de palabras como "Colombia", "acuerdos" y "paz" (con un promedio de 138 veces) que parecieran indicar el objetivo; segundo, palabras como "plebiscito", "guerra", "Gobierno", "política" y "voto" (promedio de 45) que explican lo ocurrido; y tercero, palabras que indicarían posiciones como "justicia", "conflicto", "Estado", "todos", 
"violencia", "final” y "años" (en promedio 18). En contraposición, la palabra "víctimas", categoría protagonista del proceso de negociación, solo es usada 13 veces.

Los actores políticos del proceso de paz, lámese Gobierno y oposición, tuvieron la más alta frecuencia de aparición en secciones de opinión de la prensa colombiana, el presidente Juan Manuel Santos y el expresidente y actual senador Álvaro Uribe Vélez, asunto que indica la preocupación de los medios por ofrecer a las audiencias equilibrio respecto de las posiciones a favor y en contra del plebiscito del 2 de octubre de 2016. En el ranking de aparición de nombres de personas en los artículos estudiados, aparecen los negociadores del proceso de paz Humberto de la Calle (jefe de la comisión del Gobierno) y Timochenko (jefe de las FARC). En tercer grado de frecuencia, aparecen diversos personajes de la política nacional e internacional con algún nivel de injerencia en el proceso colombiano.

Un comportamiento similar al reseñado en el punto anterior tuvieron las instituciones relacionadas con el proceso de paz en Colombia. En primer lugar, el Estado colombiano (Gobierno, Estado, Presidencia de la República y Ministerio de Hacienda) con 212 menciones, seguido de las FARC con 201 menciones. En segundo lugar, aparecen instituciones representativas de los otros poderes del Estado, como Congreso y Senado, Corte Constitucional, Consejo de Estado, Corte Suprema de Justicia y Fiscalía General de la Nación, y algunos organismos internacionales que tienen alta relación con el proceso de paz, como la ONU, la UE y la Corte Penal Internacional. En tercer lugar, partidos políticos como el Centro Democrático, el Partido Liberal, Cambio Radical y la Unión Patriótica; y, por último, organismos de seguridad del Estado, como las Fuerzas Armadas y el Ejército.

Y para cerrar, la prensa trató de mostrarse imparcial al evitar juicios de valor respecto de los actores de la discusión pública sobre el plebiscito; fueron mínimas las referencias para calificar de manera positiva o negativa a Gobierno, guerrilla y oposición (15\%). Sin embargo, cuando se contó la frecuencia de aparición de los nombres, se observa prelación a quienes re- 
presentan la institucionalidad gubernamental y la oposición, muy por encima de nombres relacionados con las FARC.

\section{Reflexiones finales sobre la coyuntura nacional e internacional respecto de la desconexión con los ciudadanos de las élites políticas y medios de comunicación}

En los casos ocurridos en Colombia, el Reino Unido y los Estados Unidos en 2016 (los dos últimos citados en la introducción de este artículo), el denominador común fue la desconexión de las élites (poderes políticos, económicos y mediáticos) con los ciudadanos, lo que generó resultados adversos para quienes olvidan que el ciudadano no es un convidado de piedra en las discusiones de los asuntos públicos y que en esas controversias actúa con independencia, en cierta medida al margen de las pretendidas manipulaciones de la contraparte; como se señaló, en esa situación suele ganar la coherencia y perder la desconexión. Esa desconexión se origina en la tendencia de las organizaciones, tanto públicas como privadas, a hablar mucho y oír poco, lo que reclama como elemento de primera categoría en la comunicación pública a "la escucha”, llevando por fin a la práctica el asunto suficientemente teorizado de la bidireccionalidad: "la expresión de la voz está en reciprocidad con la escucha, la voz está extendidamente malinterpretada y puesta en práctica como habla, con poca o ninguna atención a quien escucha y a cómo puede efectivamente conseguirse escuchar [la traducción es mía]" (Macnamara, 2015, p. 7). Los ciudadanos, célula prima de la democracia, tienen mucho que decir, y cuando se les escucha, se les reconoce, se les presta atención, se les comprende, se les otorga consideración y se les responde, se revigoriza la esfera pública con el aumento de participación ciudadana y con el incremento de la confianza en el Gobierno y en las instituciones (Macnamara, 2015).

La postura ciudadana frente a los temas neurálgicos de la negociación de paz en La Habana fue la misma de principio a fin; los ciudadanos expresaron reticencia ante la posibilidad de perdonar a las FARC y la eventual participación en política de los insurgentes desmovilizados; y se mostra- 
ron un poco más flexibles en cuanto a las posibilidades de reincorporación a la vida civil de los desmovilizados y la alternatividad penal para el castigo de los delitos cometidos por los guerrilleros. Esa postura no fue advertida por las partes negociadoras, que calcularon que con informar de manera somera lo acordado en La Habana durante la campaña electoral del plebiscito lograrían la mayoría de votos por el Sí, recurrieron a la simplificación al suscribir al plano de lo emocional un tema de semejante complejidad (Gómez Restrepo, 2016) y, por último, se conformaron con diseminar el mensaje pasando por alto la comunicación de doble vía. Estos escollos, inclusive hoy (casi quince meses después de firmado el acuerdo), no se han superado. Las heridas producidas por la guerra son profundas, siguen abiertas y exigen serio y cuidado compromiso.

\section{Referencias}

Aarøe, L. (2011). Investigating frame strength: The case of episodic and thematic frames. Political Communication, 28(2), 207-226. https:// doi.org/10.1080/10584609.2011.568041

Abad Faciolince, H. (2016, octubre 1). Ritmo de rap por el Sí. El Espectador. Recuperado de https://www.elespectador.com/opinion/opinion/ritmo-de-rap-por-el-si-columna-657975

Amón, R. (2016, noviembre 13). De la telerrealidad a la Casa Blanca. El País. Recuperado de https://elpais.com/internacional/2016/11/10/ actualidad/1478801792_086557.html

ANSA Latina. (2016, diciembre 9). Postfactual es la palabra del año. Recuperado de http://www.ansalatina.com/americalatina/ noticia/sociedad/2016/12/09/postfactual-es-la-palabra-delano_4c942559-83fc-49ae-b028-d8915cba36ee.html

BBC Mundo. (2016, junio 24) Qué es el brexit y cómo puede afectar a Reino Unido y a la Unión Europea. Recuperado de https: / / www.bbc. com/mundo/noticias-internacional-36484790 
Canel Crespo, M. J. (2009). El impacto de los sucesos imprevistos en la imagen pública de los gobiernos españoles. Anàlisi: quaderns de comunicació i cultura, 38, 219-236. Recuperado de https://ddd. uab.cat/record/51443

Cragan, J. F. y Shields, D. C. (1995). Symbolic theories in applied communication research: Bormann, Burke, and Fisher. Nueva Yersey, EE. UU.: Hampton Press.

Decreto 1391/2016, de 30 de agosto, por el cual se convoca a un plebiscito $\mathrm{y}$ se dictan otras disposiciones.

Duzán, M. J. (2016, septiembre 24). Un voto por el futuro. Semana. Recuperado de https://www.semana.com/opinion/articulo/maria-jimena-duzan-un-voto-por-el-futuro/494916

El Colombiano (2016a, sepiembre 1). La pregunta del plebiscito. Recuperado de http://www.elcolombiano.com/opinion/editoriales/lapregunta-del-plebiscito-FD4894711

El Colombiano (2016b, septiembre 18). Dos semanas para elevar el debate. Recuperado de http://www.elcolombiano.com/opinion/editoriales/dos-semanas-para-elevar-el-debate-HG4998797

El Colombiano (2016c, octubre 2). Colombia, entre el sí y el no, p. 29.

El Espectador (2016a, septiembre 24). 26 de septiembre de 2016. Recuperado de https://www.elespectador.com/opinion/editorial/26-deseptiembre-de-2016-articulo-656696

El Espectador (2016a, octubre 1). Es momento de decir sí. Recuperado de https://www.elespectador.com/opinion/editorial/momento-dedecir-si-articulo-657974 
El Heraldo (2016a, agosto 25). Una nueva etapa. Recuperado de https:// www.elheraldo.co/editorial/una-nueva-etapa-280571

El Heraldo (2016c, septiembre 30). Un sí vigilante. Recuperado de https:// www.elheraldo.co/editorial/un-si-vigilante-288987

Elpais.com.co (2016a, abril 28). La hora de la verdad. Recuperado de https:// www.elpais.com.co/opinion/editorial/la-hora-de-la-verdad.html

Elpais.com.co (2017, julio 31). Por la convivencia. Recuperado de https:// www.elpais.com.co/opinion/editorial/por-la-convivencia-1.html

El Tiempo (2016a, agosto 28). Justicia especial, pero no insular. Recuperado de https://www.eltiempo.com/opinion/editorial/justicia-especial-pero-no-insular-editorial-el-tiempo-52822

El Tiempo (2016b, octubre 2). Las razones de un sí. Recuperado de https:// www.eltiempo.com/opinion/editorial/las-razones-de-un-si-editorial-el-tiempo-54558

Entman, R. M. (2003). Cascading activation: Contesting the White House's frame after 9/11. Political Communication, 20(4), 415-432. DOI: $10.1080 / 10584600390244176$

Entman, R. M. (2004). Projections of power: Framing news, public opinion and U.S. foreign policy. Chicago, EE. UU.: University of Chicago Press.

García Gurrionero, M. (2010). La eficacia de las estrategias de comunicación del gobierno de España (2004-2008) ante el terrorismo: análisis comparado de discursos y "frames" mediáticos desde la teoría dramatística de Kenneth Burke (Tesis doctoral, Universidad Complutense de Madrid, Madrid, España).

García Gurrionero, M. (2013). El papel del terror en la sociedad. Madrid, España: Maia. 
Gómez Giraldo, J. C. (2013). La construcción de la realidad como estrategia de comunicación política ante casos conmocionantes en el gobierno del expresidente de Colombia Álvaro Uribe Vélez (Tesis doctoral, Universidad Austral, Buenos Aires, Argentina).

Gómez Giraldo, J. C. (2016, septiembre 18). Se les dio muy poco tiempo al debate y la divulgación: priman las emociones. El Colombiano. Recuperado de http://www.elcolombiano.com/opinion/contraposicion/se-les-dio-muy-poco-tiempo-al-debate-y-la-divulgacionpriman-las-emociones-AC5004266

Gómez Giraldo, J. C., Hernández Rodríguez, J. C., Gutiérrez Coba, L. M., Arango Forero, G. A. y Franco Arango, A. C. (2010). Los noticieros de la televisión colombiana "en observación": una mirada desde la academia a la estructura, cobertura y contenidos de los teleinformativos de la televisión abierta en Colombia. Palabra Clave, 13(2), 217-250. DOI: 10.5294/pacla.2010.13.2.1

Gómez Giraldo, J. C. y Cárdenas Ruiz, J. D. (2017). El papel de los medios de comunicación en el proceso de paz en Colombia: del secretismo de la mesa al vértigo del plebiscito. En A. Gil Gil, E. Maculan y S. de Sousa Ferreira (Coords.), Colombia como nuevo modelo para la justicia de transición (pp. 145-178). Madrid, España: Instituto Universitario General Gutiérrez Mellado.

Gómez Restrepo, L. F. (2016, septiembre 12). Razón de un sí. El País. Recuperado de https://www.elpais.com.co/opinion/columnistas/ luis-felipe-gomez-restrepo/razon-de-un-si.html

Infobae.com (2016, septiembre 27). Qué dicen las encuestas a cinco días del plebiscito por la paz en Colombia. Recuperado de https://www. infobae.com/america/america-latina/2016/09/27/que-dicenlas-encuestas-a-cinco-dias-del-plebiscito-por-la-paz-en-colombia/ 
Macnamara, J. (2015). Creating an 'architecture of listening' in organizations: The basis of engagement, trust, healthy democracy, social equity, and business sustainability. Sídney, Australia: University of Technology Sydney.

Martín Vivaldi, G. (1973). Géneros periodísticos. Madrid, España: Paraninfo.

Martínez, A. (2016, septiembre 19). Lo bueno del sí. El Heraldo. Recuperado de https: / / www.elheraldo.co/columnas-de-opinion/lo-bueno-del-si-286188

Martínez Albertos, J. L. (2001). Curso general de redacción periodística. Madrid, España: Thomson Learning.

Monitoreo de Medios. (s. f.). ¿De quién son los medios? Monitoreo de la propiedad MOM. Recuperado de http://www.monitoreodemedios.co/

Nieto Loaiza, R. (2016, octubre 2). ¡No! El Colombiano. Recuperado de https://bit.ly/2r1odK0

PBS Newshour. (2017, febrero 17). The latest election results from the Associated Press. Recuperado de https://to.pbs.org/2eT4y7C

Registraduría Nacional del Estado Civil. (2016). Plebiscito 2 de octubre de 2016. Recuperado de https:/ /elecciones.registraduria.gov.co/ pre_plebis_2016/99PL/DPLZZZZZZZZZZZZZZZZZ_L1.htm

Santos, J. M. (2016, octubre 2). Un fin y un comienzo: oportunidad para el futuro. El Colombiano. Recuperado de http://www.elcolombiano. com/opinion/columnistas/un-fin-y-un-comienzo-oportunidadpara-el-futuro-AN5087233

Semana (2016, septiembre 27). El Sí pierde fuerza, pero le sigue ganando al No. Recuperado de https://www.semana.com/nacion/articu- 
lo/plebiscito-por-la-paz-ultima-encuesta-de-ipsos-para-semanarcn-radio-y-rcn-television/495669

Villamizar, D. (2017). Las guerrillas en Colombia: una historia desde los orígenes hasta los confines. Bogotá, Colombia: Debate.

Watzlawick, P. (1979).¿Es real la realidad? Confusión, desinformación, comunicación. Barcelona, España: Herder. 